معايير ادارة الجودة الثاملة للمجموعة المكتبية لمكتبة كلية العلوم في جامعة زاخو : دراسة تحليلية

$$
\begin{aligned}
& \text { فادية عبدالرمن خالد } \\
& \text { فاكولتي العلوم الأنسانية، جامعة زاخو، أقليم كوردستان - العراق. } \\
& \text { (تاريخ القبول بالنشر: } 12 \text { تشريين الثانى } 2014 \text { الكانيان }
\end{aligned}
$$

: الملخص :

يهدف البحث التعريف بمفهوم ادارة الجودة الشاملة في المكتبات ومراكز المعلومات مع التركيز على تطبيق المعايير التي يجب

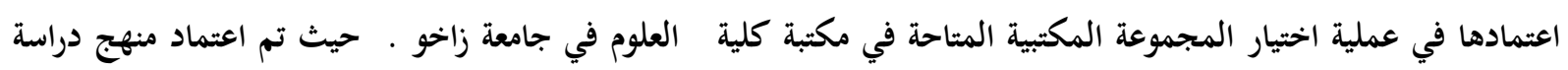
الحالة من خلال المسح الفعلي للمجموعة من الكتب في حقل الكيمياء والاعتماد على مجموعة من المعايير المعتمدة في عملية

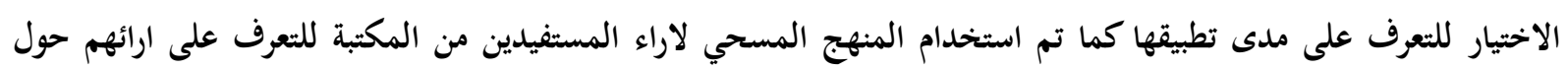

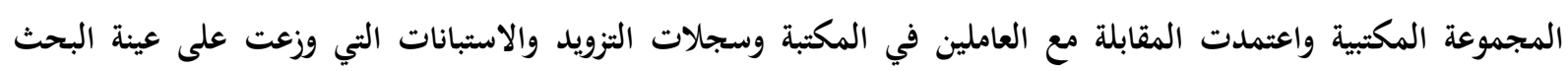
كادوات لجمع البيانات وقد خرج البحث بجملة نتائج نجملها بالاتي :

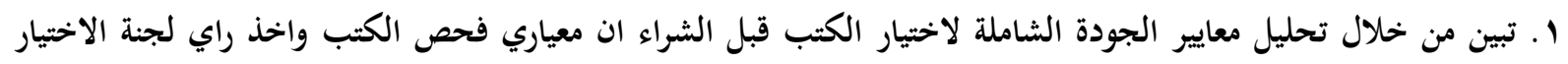

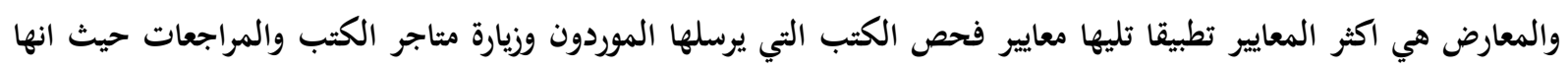
تطبق احيانا .

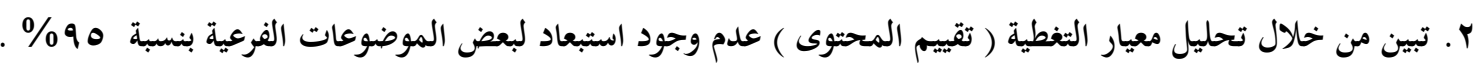
كما توصل البحث الى عدد من التوصيات منها :

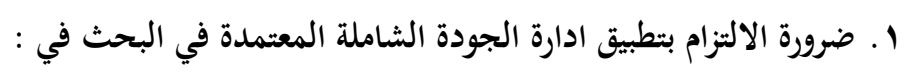

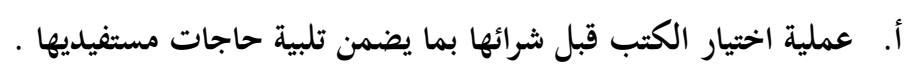

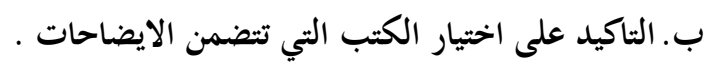

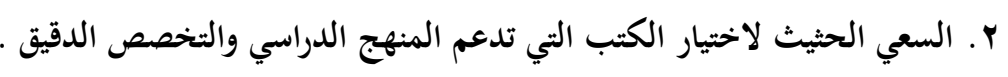

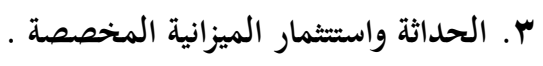

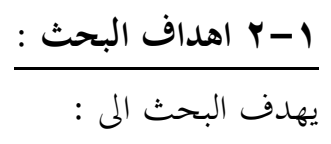

ا. التعريف بمفهوم ادارة الجودة الشاملة في المكتبات ومراكز

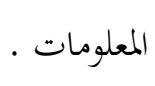
r. التعريف بمبادئ ادارة الجودة الشاملة في المكتبات ومراكز المعلومات r. التعريف باهم الاسس الواجب اتباعها عند تطبيق (التبات

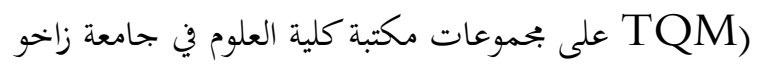
تاتي اهمية البحث من اهمية البحث : المكتبة والتي تعكس مدى كفاءة الخدمات المقدمة فيها لتلبية

$$
\text { المبحث الاول }
$$

الاطار العام للدراسة

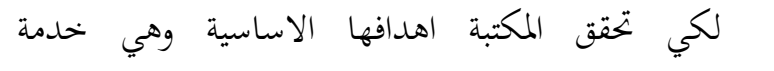
المستفيدين وتلبية احتياجاهم البحثية المختلفة بما تقدمه وهية الماسية بحموعاتما لابد من الاجابة عن التساؤلات التالية : 1. هل تطبق المكتبة معايير ادارة الجودة الشاملة في عملية اختيار وانتقاء بحموعاقا المكتبية ؟ هل ب. مامدى ملائمة مصادر المعلومات لاحتياجات المستفيدين في ضوء ادارة الجودة الشاملة؟ ملمبه 


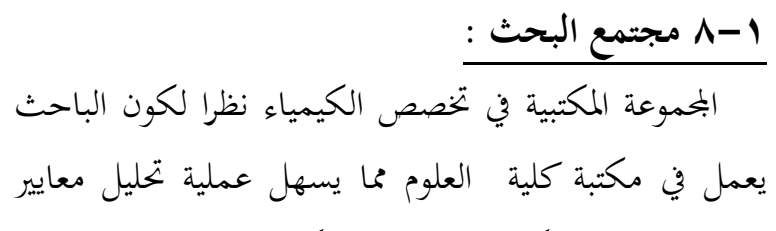
الجودة المعتمدة لكل كتاب من الكتب التي شملتها عملية المسح فقد استبعددت النسخ المكررة لنفس العنوان والكتب

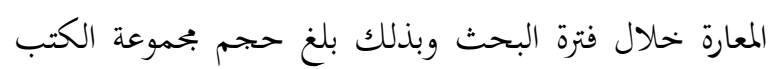

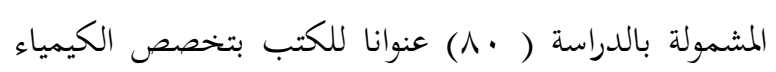

$$
\text { وباللغة الانكليزية . }
$$

وان شراء الكتب للمكتبة في اي كلية يجب استشارة

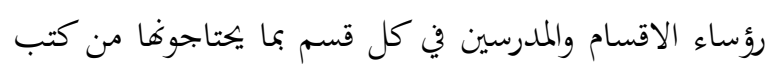

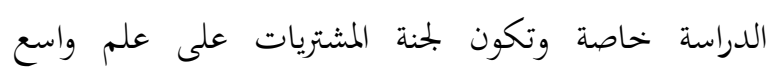
بالكتب التي تشترى للكلية .

$$
\text { المبحث الثاني }
$$

ادارة الجودة الشاملة

\section{Total Quality Management}

\section{اولاً : مفاهيم ادارة الجودة الشاملة}

ان ادارة الجودة الثاملة تمثل بصفة عامة فلسفة ادارية

مبنية على اساس رضا المستفيد وهي بذلك تضمن التصميم المتفق للمنتجات المقدمة من المؤسسة ، وتحتل ادارة الجودة الشاملة ادارة تنظيمية يمكن تطبيقها في مختلف مستويات

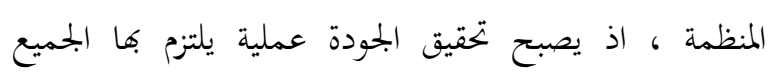

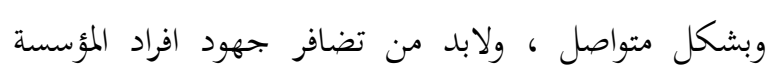

$$
\text { للوصول الى الجودة المرجوة . }
$$

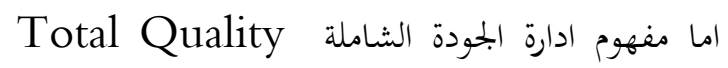
Management (T.Q.M )

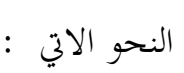

أ.الشاملة ( Total ) : التحو التحام كل موظف في المنظمة في

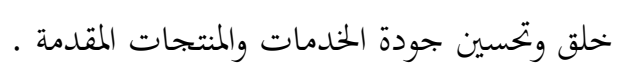
ب.الجودة (Quality) ) : تركيز المنظمة عبر الافراد العاملين بها وعبر الانشطة التي وجدات من اجلها على تقدير

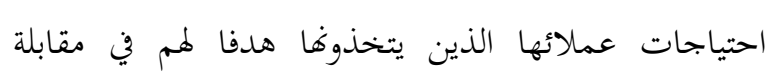

حاجات المستفيدين في اتاحة المصادر التي يرغب المستفيد في الحصول عليها وعليه تقع على عاتق المكتبة مسؤولية تامين

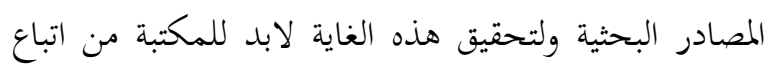

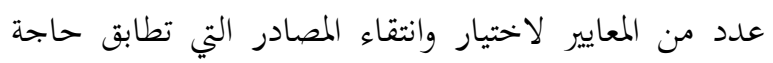
الباحث الدقيقة .

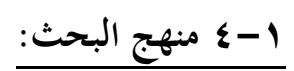

تم اعتماد منهج دراسة الحالة لواقع بحموعة الكتب متبحت الخصصة في الكيمياء وباللغة الانكليزية . 1 ا. تم اعداد استبانة موجهة لاساتذة علية العلوم قسم الكيمياء وطلبة المرحلة الرابعة فقط والتي تضمنت ثلاثة اسئلة بتسعة محاور ثانوية للتعرف على ارائهم حول المجموعة المكتبية

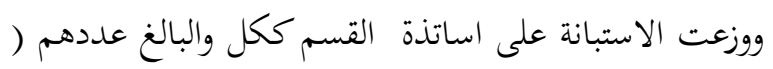
111) ، كما وزعت الاستمارات على جميع الطلبة المرحلة

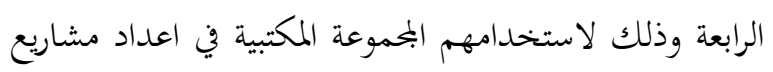

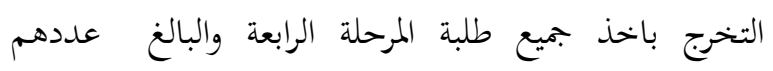

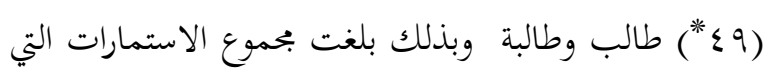

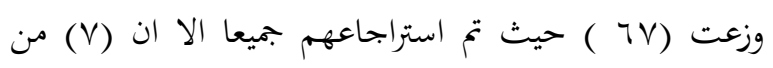

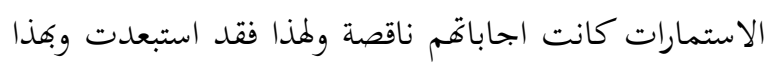

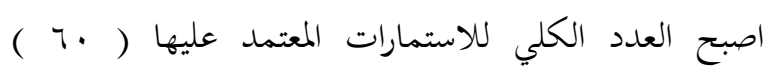

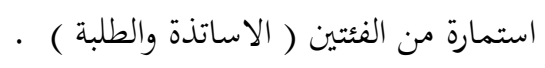

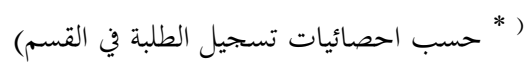

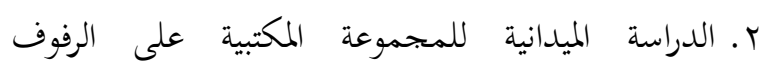
وسجلات التزويد. r. المقابلة مع مسؤولي المكتبة ضعف الاعتماد على معايير ادارة الجودة الشاملة في الفيات الختيار البحموعة المكتبية يؤدي الم ضعف المجموعة موضوعيا .

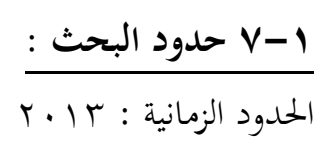

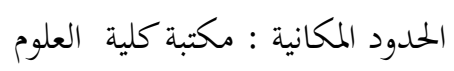
الحدود الموضوعية : الكتب المتخصصة في الكيمياء 
يحققون معدلات اداء مميزة ، وتكوين بحالس الجودة ، والتحسين المستمر للجودة .( غنيم ، م . . Y ) .

ب- مفهوم ادارة الجودة الشاملة في المكتبات

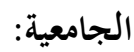

لقد ركزت تعريفات الباحثين لادارة الجودة الشاملة في

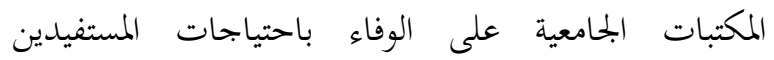
والخدمات المقدمة لهم ، حيث عرف باول موشر الجودة الشاملة بالمكتبات الجحامعية "باخا الفائدة التي تتحقق من توفير المقتنيات للمستفيدين منها للوفاء بااحتياجاهم في اعمالهم وكذلك الادارات التي تتبعها المكتبة .

ومن الباحثين من يركز في مفهومه على الحندمات

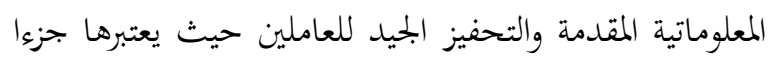

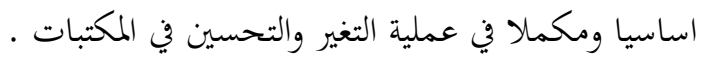
ومنهم من ركز على ثلاثة مفاهيم لادارة الجودة الشاملة

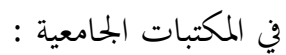
1. ت توافر التقنيات المطلوبة r. امكانية وسهولة الحصول على المقتنيات

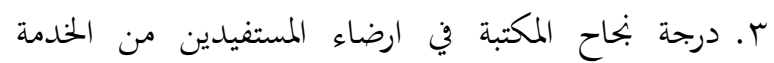

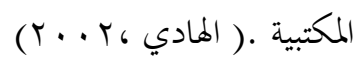

ومن خلال التعاريف السابقة في المكتبات الجامعية لادارة الجودة الشاملة بنحد ان تحقيق هدف ادارة الجودة الشاملة

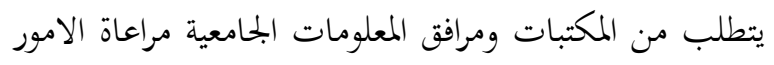

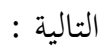
ا. الجودة هي الثقافة التي ينبغي ان تتبنى من جميع العاملين

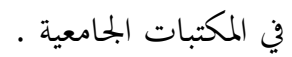
r. تغيير الثقافة المتبعة في المكتبة ، وهذا يحتاج الى الالتزام

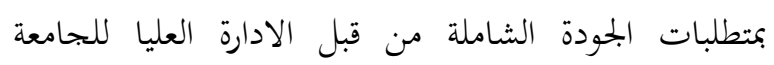

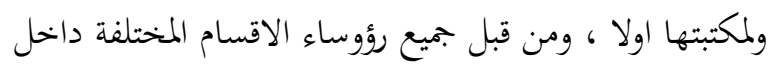

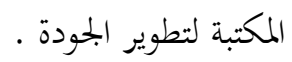
r. تمدف المككتبة الجحامعية من تطبيق ادارة الجودة الشاملة الى لى لهوده تلافي حدوث الاخطاء وليس الى كشفها فقط .
احتياجاهم ، ويساعد فهم واداراك وتمييز العميل للجودة المنظمة على تقدير كبير وعميق لها . ج. الادارة ( Management) : تكمن ادارة الجودة لانشطتها في التاكيد على التحسن المستمر لانظمة

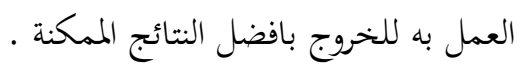

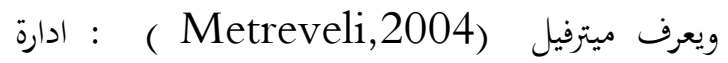
الجودة الشاملة باها تلك الفلسفة الادارية التي تعننق كل

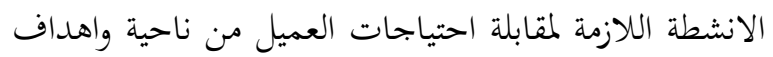
المنظمة من ناحية اخرى بطريقة مرضية وبكفاءة وربحية عالية وذلك بالاستفادة القصوى لكل امكانيات وقدرات العاملين. وقد وردت تعريفات كثيرة لعلماء اختصوا بمفاهيم الجودة

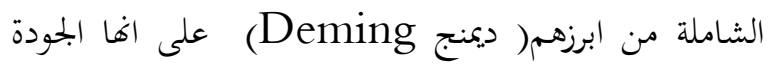

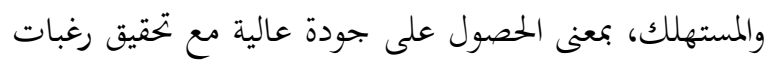

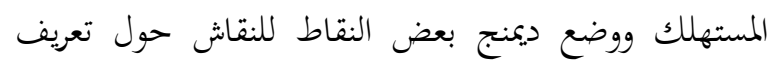

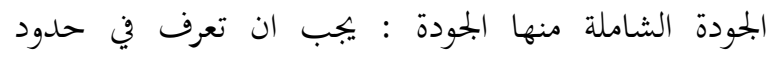

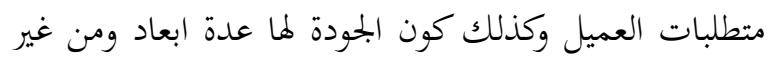

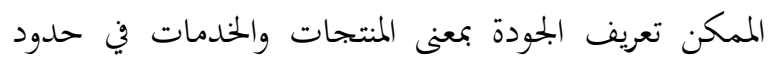
خاصية واحدة وان درجة الجودة ليست متساوية في كل

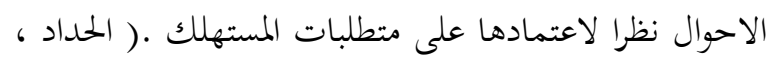
وعرف جوران ( Juran الجودة على ان لها معان كثيرة : •الجودة تحتوي على جميع مظاهر المنتج الذي يحقق احتياجات وتطلعات المستهلك من المنتج. الجودة تعرف على اها عدم وجود الحنلل في المنتج · الملائمة في الاستخدام

ولتحسين مستوى الجودة وضع كروسبي (Crosby )

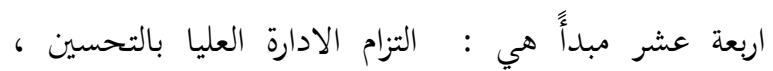
وتكوين فرق عمل لتحسين الجودة ، وقياس الجودة ، وتقويم تكلفة الجودة، ونشر الوعي بالجودة وتصحيح اجراءات العمل، وتشكيل لجنة للتخطيط للعيوب الصفرية ، وتحديد الاهداف، وازالة اسباب العيوب ، ومكافاة العاملين الذين 


\section{ا}

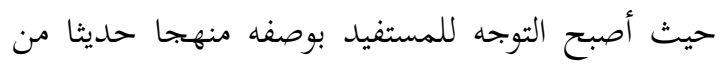

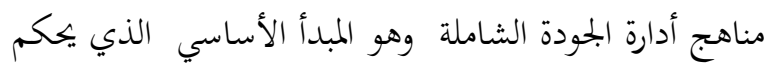
توجه المكتبات ومراكز المعلومات وعلى المكتبة تحقيق هذا

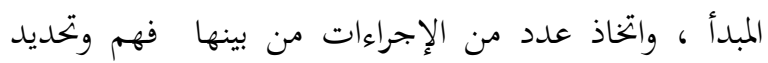

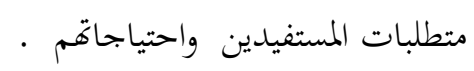
r - ب الإدارة بالحقائق

تعتمد القرارات الصائبة على خلفية من المعلومات

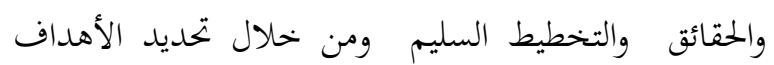
الواقعية وتوفير كل السبل التي تساهم في تحقيقها ، فيطي

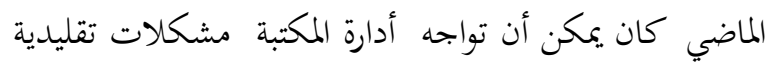
يمكن التغلب عليها من خلال تجربة المدير الشخصية ومهاراته

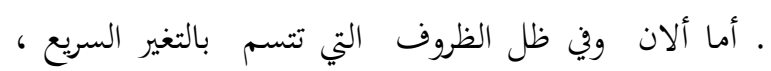

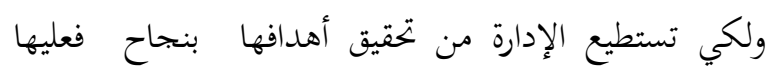

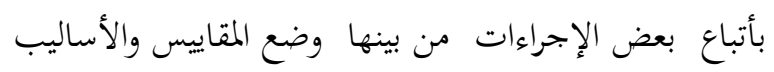
الخاصة بيجمع المعلومات عن المكتبة ونشاطاتما .

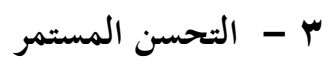

يرى خبراء الجودة أن سر بنحاح اليابان في المنافسة المبت

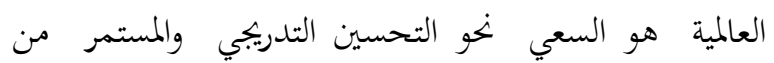

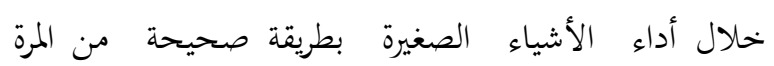

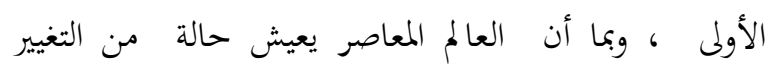

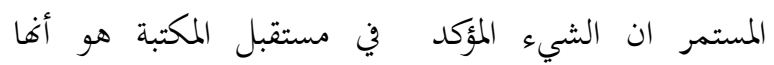

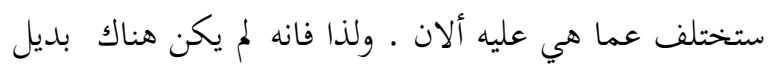

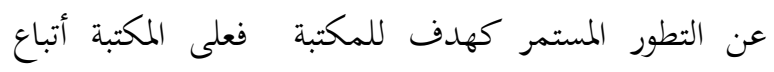

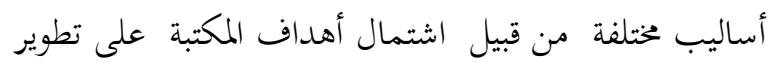

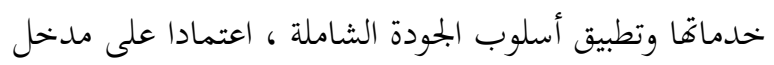

$$
\text { التطوير التدريجي خطوة / خطوة }
$$

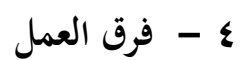

أمكانية أشراك جميع العاملين في المكتبة ومن خلال

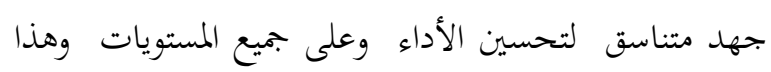
يعني وضع العاملين في فرق منتظمة بمفهوم الفرق التي تقدر قيمة التعاون والاعتماد المتبادل ولفرق العمل الكثير من فئن

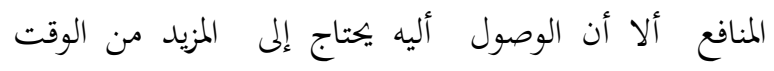

ع. تطبيق الجودة يحتاج الى جهد وتخطيط ، لاها سوف تواجه مقاومة ليست باليسيرة في بادئ الامر من قبل الذين لايؤمنون

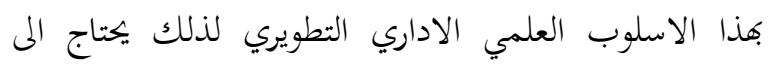

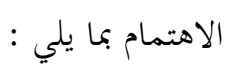
أ. التعريف بسياسة المكتبة . ب.عمل رؤية ورسالة للمكتبة تعبر عن عملها الحالي وطموحاها في المستقبل . ت. التدريب والتعليم لتوحيد لغة الجودة في المكتبة .

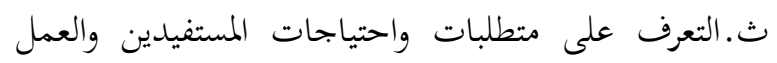

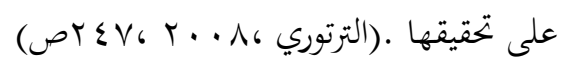
وان اهم شيئ في الكتاب العنوان والطبعة وفي المكتبة اخلاق موظفي المكتبة ومدى صبرهم مع القراء والمراجعين .

الحادعة r-1 تطبيق أدارة الجودة الشاملة في المكتبات الجامعية حظي تطبيق مبادئ أدارة الجودة الشاملة باهتمام كبير

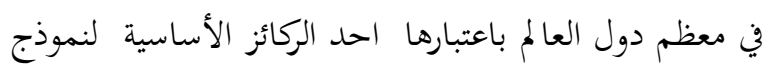

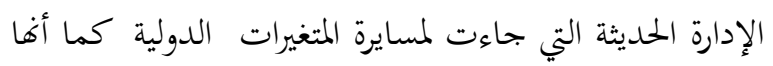
ذات أهمية كبيرة في أطار التطبيق العملي لإدارة الجودة

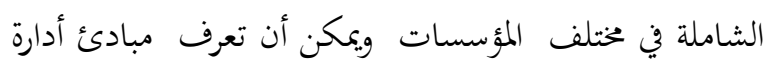

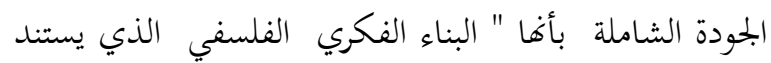

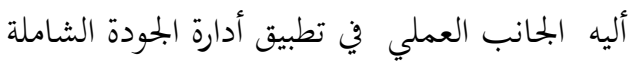

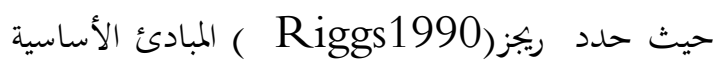
لإدارة الجودة الشاملة في المكتبات الجامعية على أهنا :-

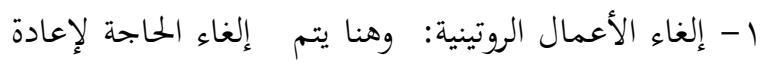

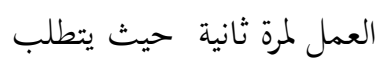
العمل بشكل صحيح من المرة الأولى .

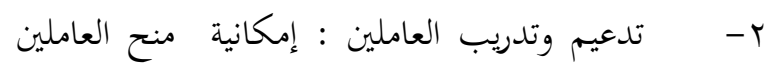

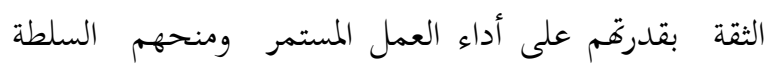

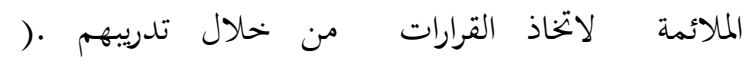

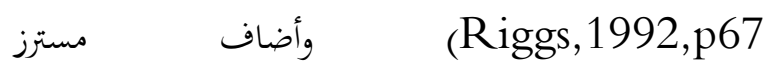
( Masters,2013) الجودة الشاملة تتم من خلال:- 
والجها والعمل الشاق ويقع هذا العمل بوجه خاص على أ أد أدارة المكتبة : وذلك يتم من خلال ضبط وتطوير النظام الإداري ،

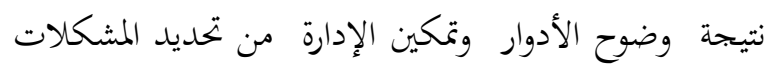

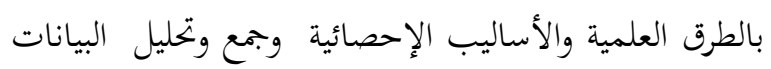

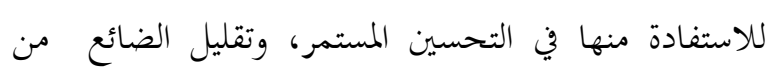
الوقت وزيادة كفاءة الخدمات r وهنا تتمثل فوائد التطبيق بالنسبة للعاملين في توفير جو النواني

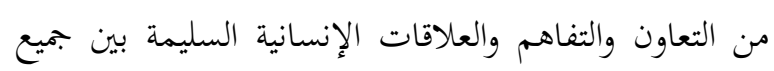
العاملين .وزيادة كفاءهم ورفع مستوى الأداء ب- المستفيدون من المكتبة : حيث تستخدم فوائد التطبيق في بحال ضبط الشكاوى

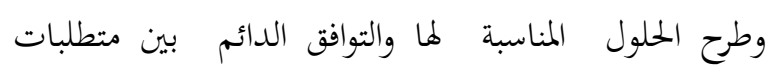

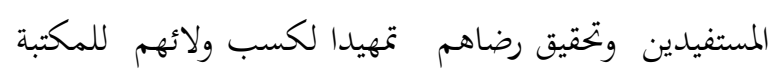

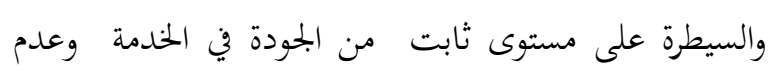
تذبذبها هبوطا 'وبالتالي فان الفائدة الكبرى لتأكيد أدارة الجودة الشاملة للمكتبة هو إسناد الإدارة العليا في اتخاذ القرار

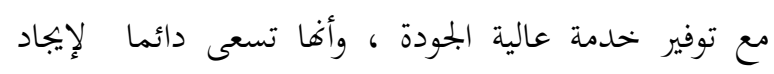

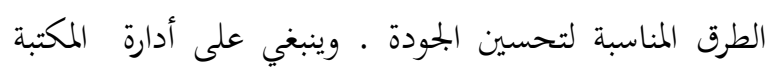

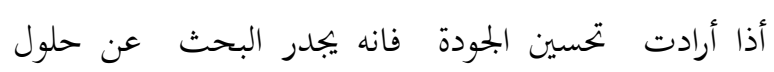

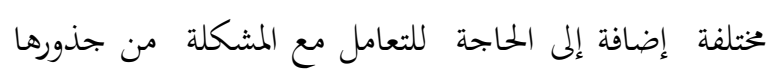

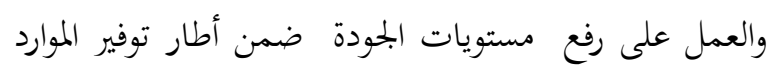
المتاحة. ( corak , 1993 .p22)

\section{ץ-1- ع اهداف ادارة الجودة الشاملة في المكتبات}

تجدف ادارة الجودة الشاملة الى تحقيق بحموعة من

$$
\text { الاهداف ومنها : }
$$

ا ـ التخطيط الاستراتيجي للمكتبات ومراكز المعلومات r. بناء القدرات المؤسسية للمكتبات ومراكز المعلومات

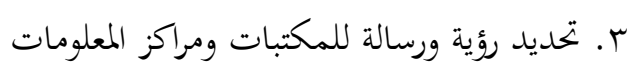

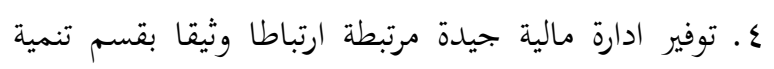
المقتنيات بالمكتبات ومراكز المعلومات .

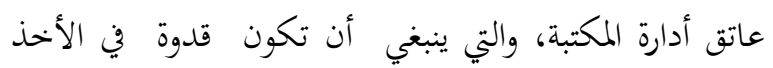
بمبدأ التعاون وفرق العمل ـ وينبغي على المدراء توفير الموارد

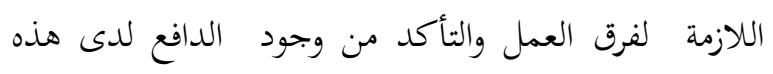

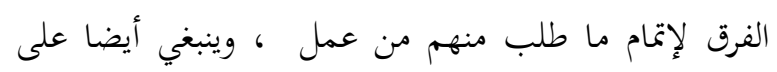

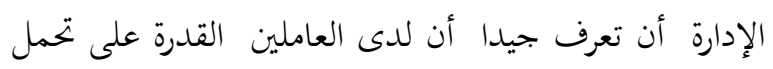

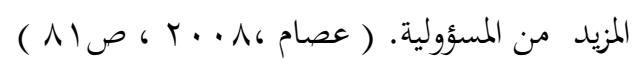

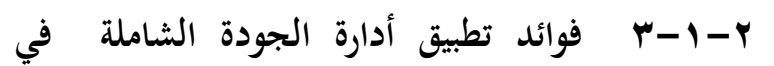
المكتبات الجامعية

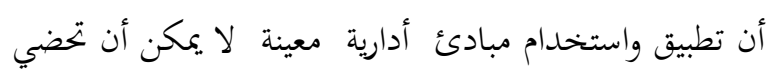

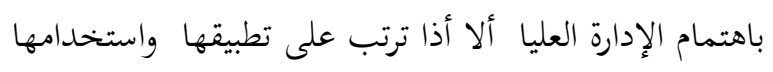

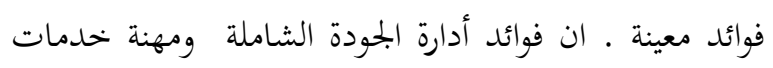

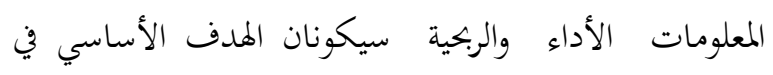

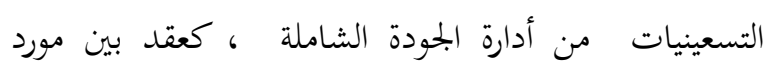

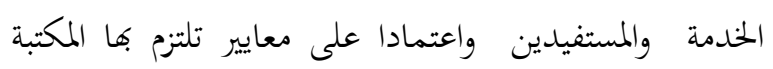
في تقديم الحدمة ـ ويمكن أجمال فوائد تطبيق أدارة الجودة

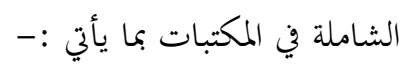
1. توفير الأداة لقياس الأداء في بحال خحدمات المعلومات.

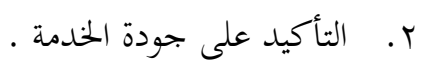
r. توفير المزايا في بحال التسويق والعلاقات العامة.

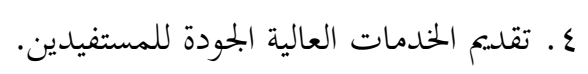

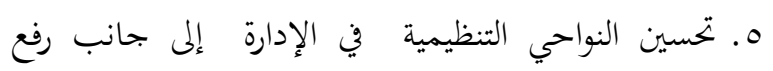
كفاءة أدائها. 7. تحسين ورفع الروح المعنوية للعاملين في المكتبات ومراكز

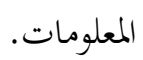
V ت تنمية وتدعيم حلقة الربط الحيوية بين خدمات

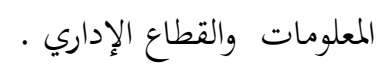

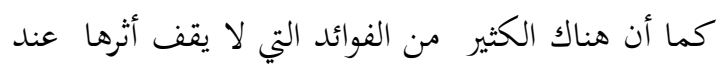

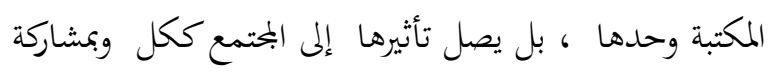
المكتبة كعنصر فاعل ويمكن تقسيم فوائد أدارة الجودة الشاملة

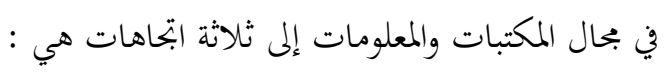




\section{اولاً : تقسيم المعلومات حسب م-Y المكال الموعة المكتبية}

Primary

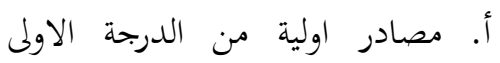

Sources

Secondaey ب.مصادر ثنانوية من الدرجة الثانية

Sources

Third Class

ت.مصادر من الدرجة الثالثة

Sources

ث. اي معلومة ولو كانت صغيرة لاعملها . ثانياً : تقسيم المعلومات حسب الشكل ولت المادي صغيرة لاكملات

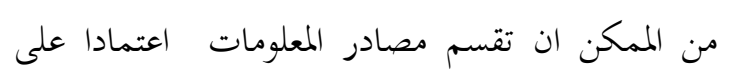

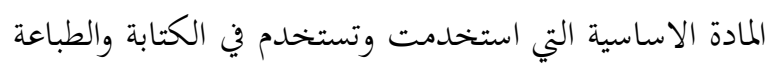
الى ثلاثة انواع رئيسية واخرى فرعية وكالاتي : ا ـ المصادر ماقبل الورقية ومنها :

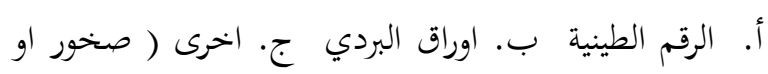
كتابات على الجحدران او على الجبال )

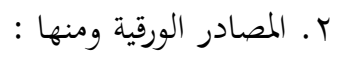
أ. المخطوطات ب. ب. الكتب ج. الدورئات د. د. الرسائل الجامعية ، التقارير

r. المصادر مابعد الورقية وتسمى بالمصادر اللاورقية ومنها أ. المصادر السمعية والبصرية ب. المصغرات ج. المصادر

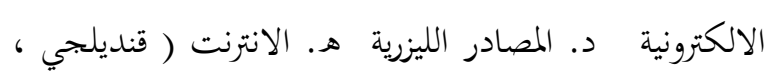

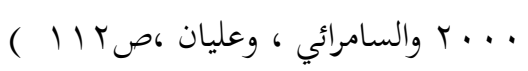

S

من اهم المعايير المستخدمة لتقييم البحموعة قبل اختيارها مايلي :

1. المستفيدون هم الاساس في اختيار المحموعة حيث يجب تحديد طلبات وحاجات المستفيدين فكلما تحددت هذه

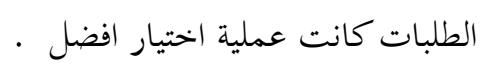

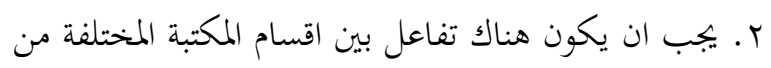
جهة من خلال العلاقات والمقابلات الشخصية لتسهيل

$$
\text { 7. } 1 \text { ـ ارضاء المستفيدين من المكتبات وتلبية احتياجاقم }
$$

V. تنمية الموارد البشرية في المكتبات ومراكز المعلومات لعمل ئمات

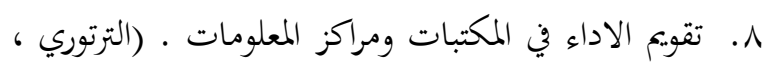

( $r \leqslant 7$ ص $r$. . . 9

ثانياً : المجموعة المكتبية ( Library

(Collecation

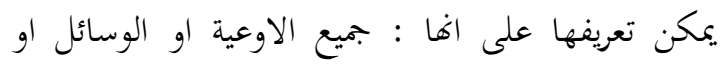

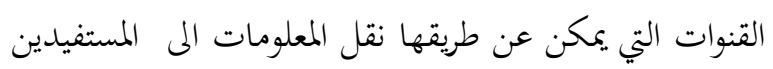

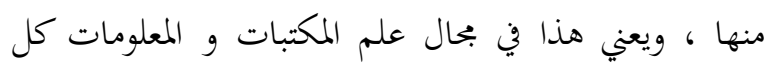

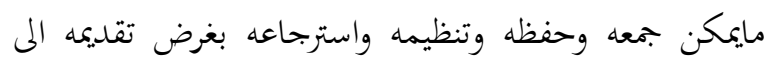

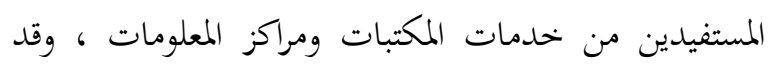

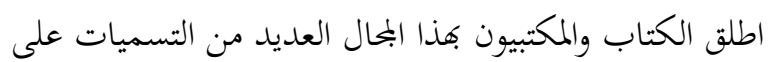

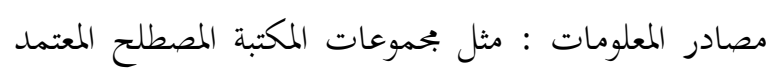
في البحث او المقتنيات او وسائل المعلومات او اوعية المعرفة . وعرفت ايضا على اها : اي نظام في اي وسط يعتمد

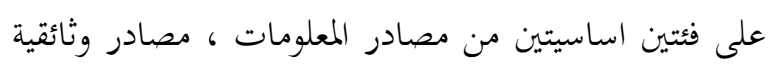
وغير وثائقية ، وهي بداية اي مرحلة لبث المعلومات تبدأ

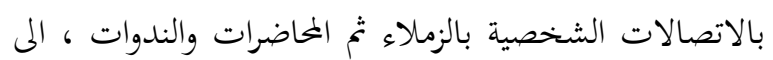

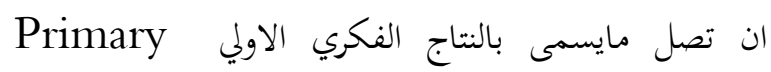
. Literatre ويمكن ان نعرف مصادر المعلومات باها كافة المواد التي

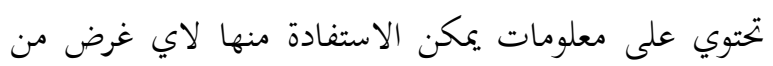

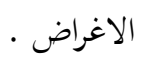
او هي كل ماتشتمل عليه المكتبة ، او مايتوفر فيها من

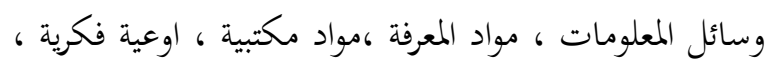
موجودات المكتبة ، مجموعات المكتبة ، الاشكال المكتبية ،مصادر المعلومات تسميات لمدلول واحد مات مات نسميه

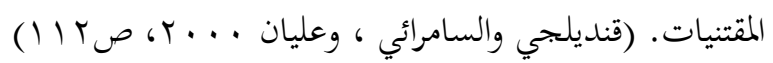


بحموعتها المكتبية حيث ترتبط باحتياجات البرامج التي تقدمها

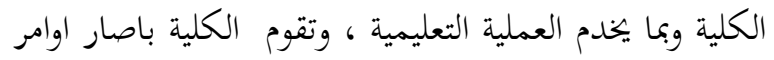
ادارية لغرض تقويم المكتبة من خلال عملية الجرد لمقتنيات

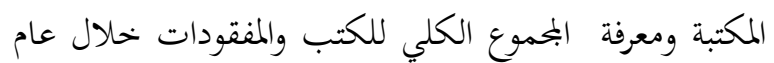
حيث تتكون من قاعة كبيرة مصممة اصلا مكتبة وقد احتوت

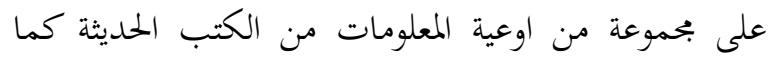

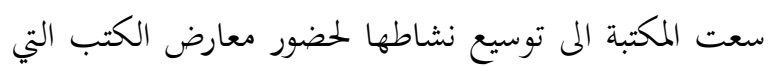
تقام في القطر حسب الميزانية التي تخصصها الجامعة للشراء

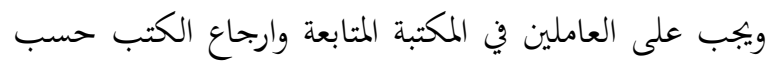

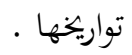
تضم المكتبة كتباً علمية فقط وباللغة الانكليزية فقط حيث بلغ بحموع عناوين الكتب ( 5725 ) عنوان كتابا اما

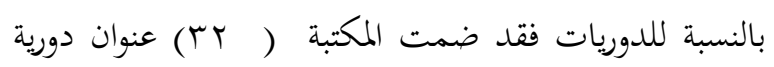
في التخصص العلمي والاطاريح ورسائل الماجستير فقد تضمنت ( TالT) عنوان والمراجع ( (T) عنوان والاقراص الليزرية ( •.0) عنوان ، تغطي التخصصات الانفة الذكر .

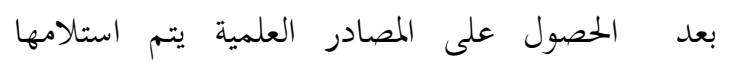

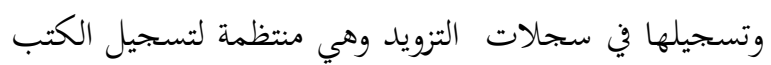

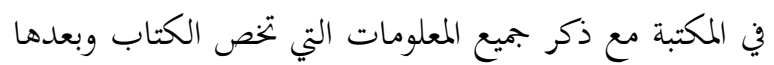

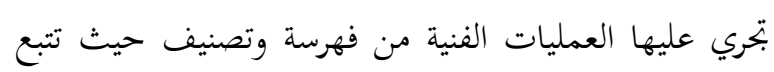

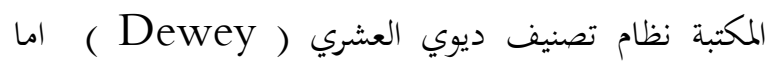
الفهرسة فتعتمد على نظام ( Cutter ) الخاص بالمؤلفين

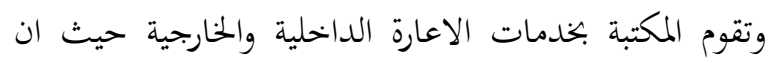
الاستعارة الداخلية تسجل في السجل الخاص بالاعارة الداخلية اما في الاعارة الخارجية عن طريق تسجيل كافة

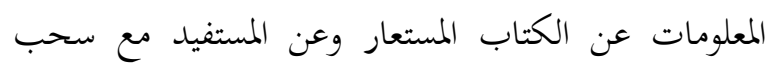
هوية المكتبة . ب-1 معايير الجودة الشاملة لاختيار الكتب* في في في في المكتبة قيد الدراسة إير الجودة ( * انظر الملحق رقم (1) الخاص بمعايير الجودة الشاملة لاختيار الكتب)

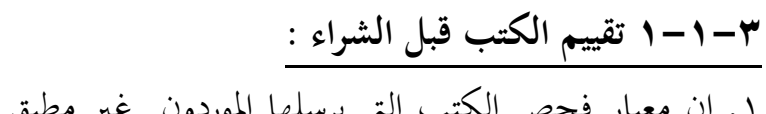

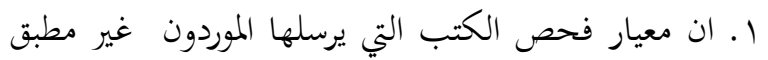
في المكتبة اذيجب ان يتم فحص الكتب قبل اقتنائها وتحديد
تحديد احتياجات كل قسم مباشرة بما يخدم المستفيدين واقامة علاقات بين رؤساء الاقسام والمستفيدين من جهة اخرى . r. لابد من الاحتفاظ بسجل تدون فيه بيانات عن المصادر

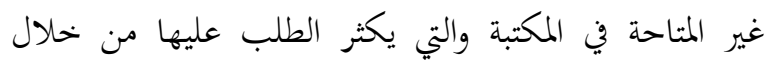
سجلات الاستعارة ، ولابد من توفر مثل هذه السجلات في فئي المكتبة . ع. لابد من التعامل مع طلبات او استفسارات المستفيدين بطريقة منهجية دون تسرع وذلك للتحديد الدقيق لنوعية مصادر المعلومات التي تلبي حاجات المستفيدين سواء تم الخصول عليها عن طريق الشراء او عن طريق اخر كالاستعارة

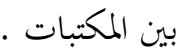
ه. يجب مراجعة كل الوسائل المتاحة للحصول على اكبر قدر

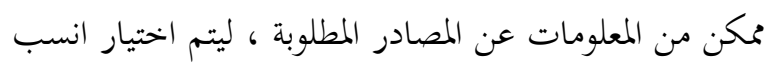

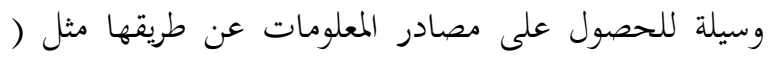
الشراء او الاشتراك في خدمات المعلومات بدون شراء نسخة

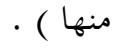
7. التدريب على التعامل مع التكنولوجيا الحديثة وخاصة

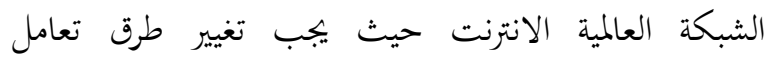
المكتبات ومؤسسات المعلومات مع الموردين من خحلالها وكذلك امكانية الوصول الالكتروني لمصادر المعلومات الالكترونية باقل كلفة ومن اي مكان ـ (بحموعة من الخبراء ،

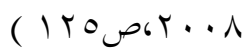
ويجب ان تعتمد المكتبة على امين مكتبة ويجب ان يكون اختصاص (معلومات ومكتبات) لتكون المكتبة اشمل وافضل. ثالثاً : مكتبة كلية العلوم

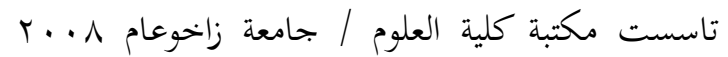
تقوم على خحمة المستفيدين من طلبة الدراسة الاولية الدراسات العليا والتدريسيين وتقوم بتوفير المصادر العلمية

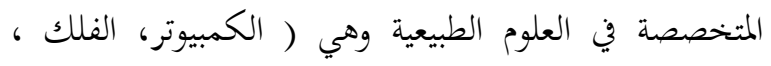

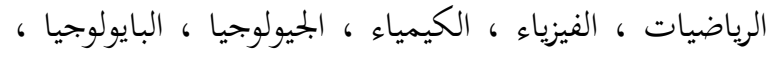

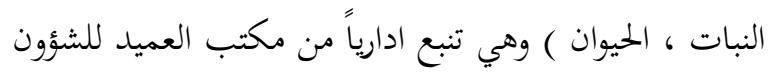
العلمية حيث تتوفر لدى مكتبة الكلية سياسة واضحة لتنمية 
( )* وتعد احد الوسائل الاساسية التي تساعد في عملية الاختيار وهي تمد الخبراء بتعريفات للموضوعات وتبرز اهم ميزاتما وتشير الى اوجهه

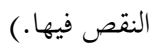

\section{r-1-1 : معيار التغطية ( تقييم المحتوى *بالنسبة}

("تمت الاستعانة باراء التدريسيين من ذوي الاختصاص للتاكد)

\section{اولا : التغطية الموضوعية}

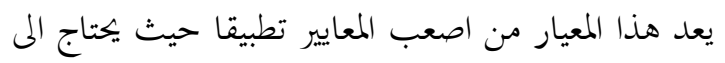

خبرة طويلة في المحال الموضوعي لتقييم شنمولية او ضيق تغطية كل مصدر ولتحقيق دقة التقييم قمنا بتصفح كل كتاب ابتداءا من صفحة العنوان والمقدمة او التمهيد وصفحة المحتويات ثم الانتقال الى متن النص حيث جاءت لعنم

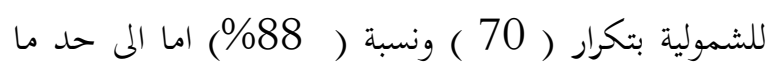
فكانت بتكرار ( 10 ) ونسبة ( 12\% ) اما لا فكانت صفرا - مف

** ثانيا : استبعاد لبعض الموضوعات الفرعية

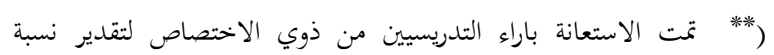

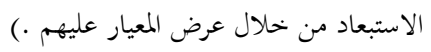

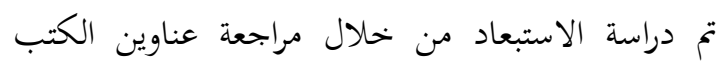
وقوائم المحتويات ومقدمة الكتاب ومقدمة الفصول والمباحث والعناوين الثانوية لكل فصل او مبحث ومقارنتها مع محتوى النص الكامل ، وقد لوحظ ان بعض_الكتب قيد الدراسة يحمل عنوانا شاملا يفترض فيه تغطية عدة موضوعات ذات علاقة ببعضها الا ان فصول مباحث هذه الكتب لم تتضمن التغطية الوافية لمثل هذه الموضوعات حيث اختلف احيانا للاستبعاد يتكرار( ع ) ونسبة ( 0ه\%) واما كلا للاستبعاد فكان بتكرار ( V7) ونسبة ( 90 \%

ثالثا: الحداثة

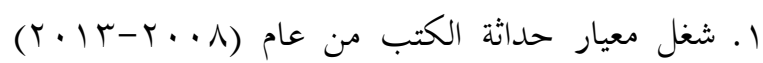

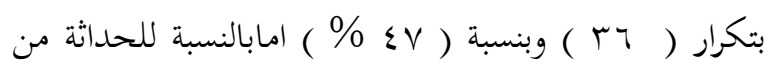

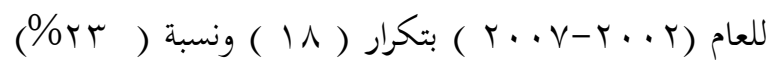

ما اذ سيتم شراؤها ام لا وذلك بالتعاون والتنسيق بين اعضاء لجنة الاختيار والعاملين في المكتبة . r. ان معيار فحص الكتب واخذ رأي لجنة الاختيار مطبق في المكتبة حيث تتالف لجنة انتقاء الكتب من عدد من التدريسيين فقط من مختلف الاختصاصات العلمية في الجامعة اي لاتوجد في اللجنة امين المكتبة او احد العاملين في المكتبة بعد توفير التخصيصات المالية للشراء من قبل الجامعة حيث يتم اجتماع اللجنة لاختيار العناوين المرغوبة من بين العناوين المعروضة من قوائم الناشرين ويتم الانتقاء من قبل اعضاء اللجنة وحسب الميزانية المخصصة لشراء . r. ان معيار زيارة متاجر (باعة) الكتب غير مطبق في المكتبة. ع. معيار فحص النسخ : يقوم بعض الناشرين احيانا باعطاء

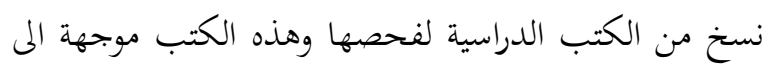
الاساتذة وليس الى امناء المكتبات حيث يعرض الناشر نسخا الى اعضاء الميئة التدريسية للثنهم على ترشيحها الى الطلبة وهذا المعيار غير مطبق في المكتبة . ه. المراجعات Review المراجعات والتي تصدر في الصحف والدوريات المتخصصة موضوعيا غير مطبق في المكتبة 7. ان معيار الاعارة بين المكتبات غير مطبق في المكتبة .

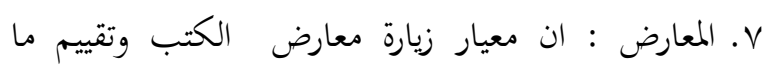
معروض فيها من عناوين مطبق في المكتبة حيث يقوم بحموعة من اعضاء الهيئة التدريسية بزيارة المعارض وشرواء مايحتاجه القسم من الكتب المتخصصة . 1. محتوى اللغة : يعتبر المحتوى اللغوي وكلفة الكتاب معيار من المعايير الاساسية فلهذا فقد كانت المكتبة تفتقد الى هذا المعيار فقد كانت الكتب العلمية جميعها باللغة العبية والانكليزية ولاتوجد كتب علمية باللغة الكردية وخحاصة ان غالبية الطلاب لم يجيدون اللغات الاخرى ومن ضمنها العربية لكون الجامعة في زاخو وهم بحتمع كردي ويتكلم لغة الام ( اللغة الكردية ) 


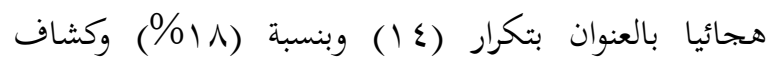

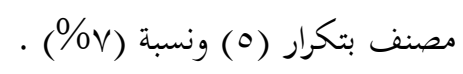
r. احتل شكل الكشاف ككشاف مع الكتاب نفسه بتكرار

$$
\text { . ( ) (V ) (V) }
$$

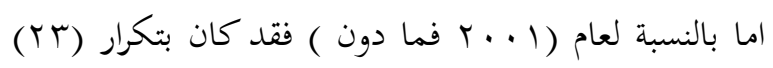

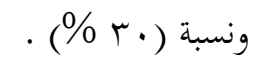

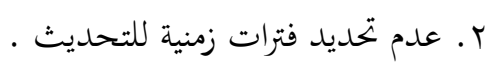

\section{رابعاً: : الجودة والكفاءة}

احتل معيار مكانة الناشر لمؤسسة او هيئة بتحارية بتكرار سادسا : التكاليف

1. معيار سعر شراء الكتاب غير مرتفع حيث جاء بتكرار

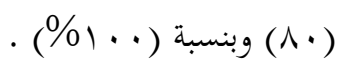
r. مصادر الحصول على المصدر بكلفة اقل سجلت احيانا،

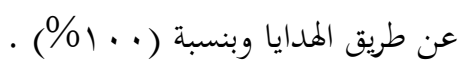

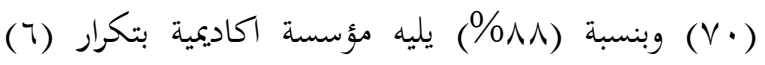

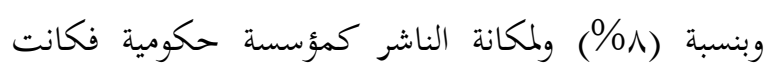

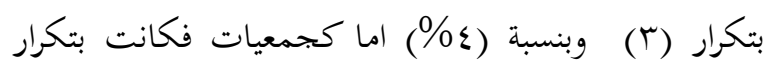

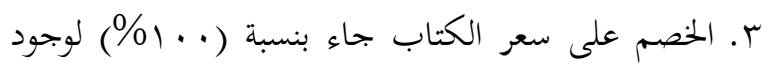

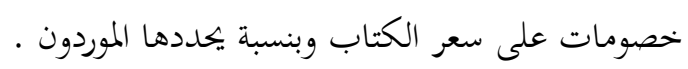

$$
\text { سابعا: المصادر البديلة }
$$

حقق هذا المعيار نسبة (•و\%) اقراص ليزرية وذلك لان

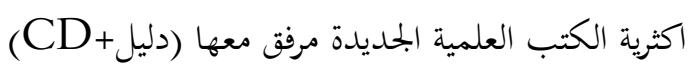

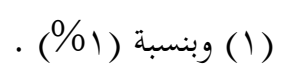

خامساً : التكشيف

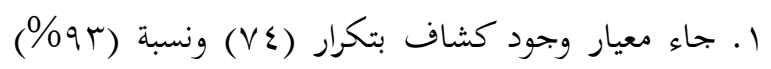

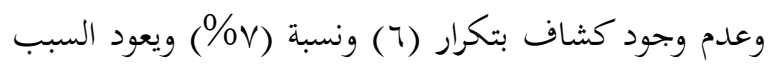
في ذلك ان البمموعة المدروسة هي باللغة الانكليزية وان غالبية الكتب باللغة الانكليزية تتضمن كشافات فالكشاف يسهل

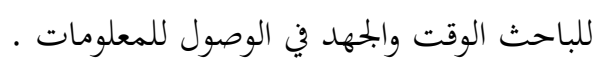

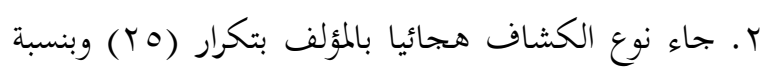

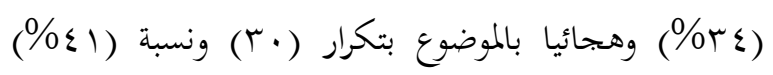

ب-1-1-ب تحليل اسئلة الاستبيان الموجه للمستفيدين كمعيار لمدى ملائمة مجموعة الكتب في المكتبة قيد الدراسة

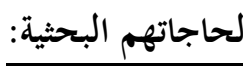

\begin{tabular}{|c|c|c|c|}
\hline النسبة & التكرار & الفئات & ت \\
\hline \%ro & 10 & التدريسيين & 1 \\
\hline$\% v_{0}$ & $\varepsilon 0$ & الطلبة & r \\
\hline$\% 1 \ldots$ & 7. & المجموع & $r$ \\
\hline
\end{tabular}

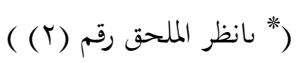

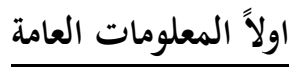

جدول رقم (1) 
يبين الجدول رقم (1) اعلاه عدد العينة المشمولين في اعداد البحث حيث بلغ عدد العينة الكلي (• ج) فقد بلغ عدد اعضاء

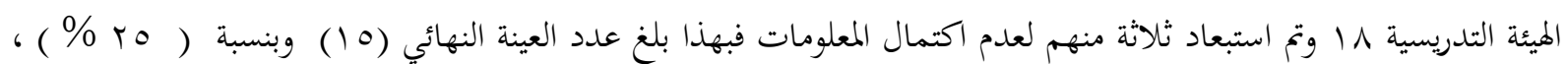

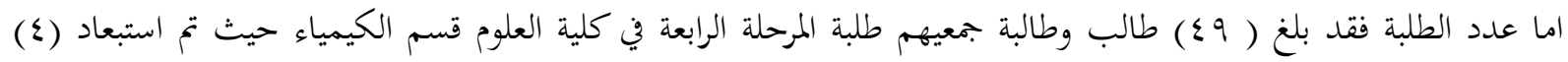

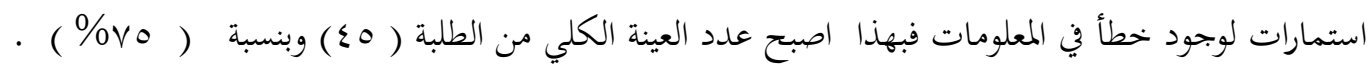

\begin{tabular}{|c|c|c|c|c|c|c|c|c|}
\hline \multirow{2}{*}{ المجموع } & \multicolumn{2}{|c|}{ مدرس مساعد } & \multicolumn{2}{|c|}{ مدرس } & \multicolumn{2}{|c|}{ استاذ مساعد } & \multicolumn{2}{|c|}{ استاذ } \\
\hline & $\%$ & التكرار & $\%$ & التكرار & $\%$ & التكرار & $\%$ & التكرار \\
\hline 10 & $\varepsilon$. & 0 & \%rr & 0 & \%r. & $r$ & \%।r & r \\
\hline
\end{tabular}

يبين الجحدول رقم (Y) اعلاه عدد اعضاء الهيئة التدريسية (10) حيث بلغ عدد التدريسيين من درجة استاذ (r) وبنسبة

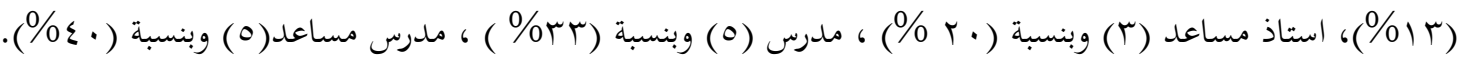

\begin{tabular}{|c|c|c|c|c|c|c|c|}
\hline \multirow{3}{*}{ المجموع } & \multicolumn{6}{|c|}{ استخدام مجموعة الكتب في المكتبة قيد الدراسة } & \multirow{3}{*}{ الفئات } \\
\hline & \multicolumn{2}{|c|}{ كلا } & \multicolumn{2}{|c|}{ احيانا } & \multicolumn{2}{|c|}{ نعم } & \\
\hline & النسبة & التكرار & $\%$ & التكرار & $\%$ & التكرار & \\
\hline 10 & \%r. & $r$ & $\% v$ & 1 & $\%$ rr & 11 & لتدريسيين \\
\hline 纟o & $\% 11$ & 。 & $\% 11$ & 0 & $\% \vee \wedge$ & ro & الطلبة \\
\hline 7. & $\%$ & $\wedge$ & $\% 1$. & 7 & $\% \vee v$ & $\varepsilon 7$ & البحموع \\
\hline
\end{tabular}

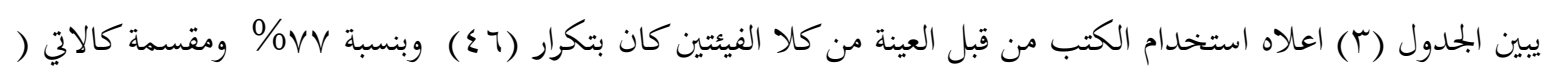

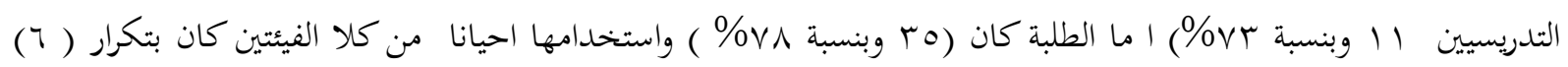

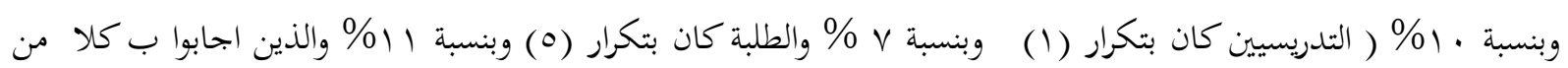

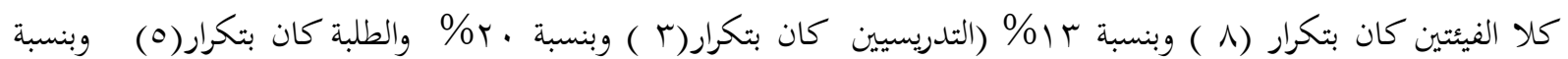
$\% 1 r$ سوف يتم استبعاد (r) من اعضاء الهيئة التدريسية و (0) من الطلبة لاغم اجابوا باهم لايستخدمون الكتب الموجودة في

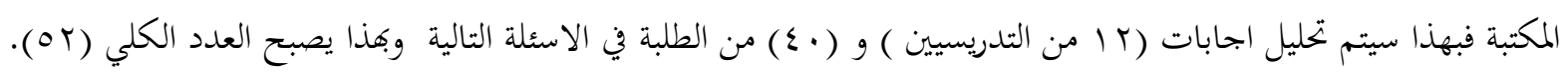
جدول رقم (๕) يبين حداثة كتب المكتبة قيد الدراسة

\begin{tabular}{|c|c|c|c|c|c|c|c|}
\hline \multirow{3}{*}{ المجموع } & \multicolumn{6}{|c|}{ الحداثة } & \multirow{3}{*}{ الفئات } \\
\hline & \multicolumn{2}{|c|}{ كلا } & \multicolumn{2}{|c|}{ احيانا } & \multicolumn{2}{|c|}{ نعم } & \\
\hline & النسبة & التكرار & $\%$ & التكرار & $\%$ & التكرار & \\
\hline Ir & $\% \wedge$ & 1 & \%ro & $r$ & $\%$ \% & $\wedge$ & التدريسيين \\
\hline$\varepsilon$. & $\% 10$ & 7 & \%ro & 1. & $\%$ \% & $r \varepsilon$ & الطلبة \\
\hline or & $\%$ & v & \%ro & Ir & \% & rT & البجموع \\
\hline
\end{tabular}


ץ-أ يبين الجدول ( ع ) اجابات بحموع العينة التي اجابت بان بجموعة الكتب المتاحة للمستفيدين في مكتبة كلية العلوم تتسم

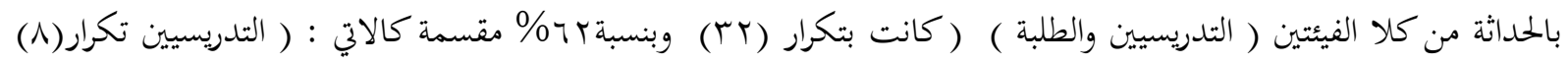

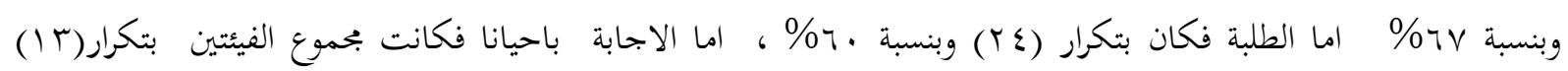

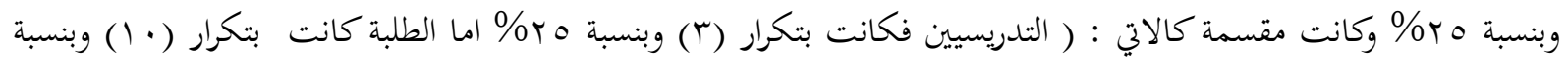

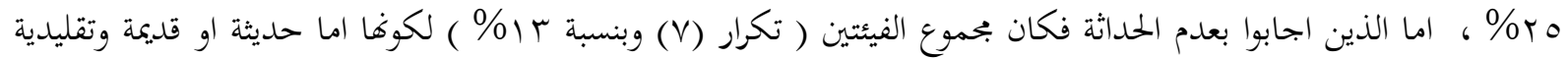

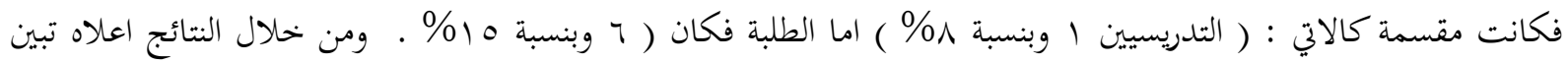

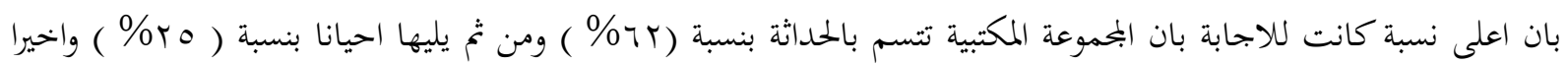

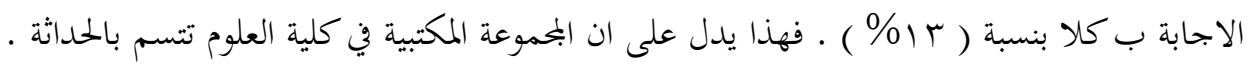

\begin{tabular}{|c|c|c|c|c|c|c|c|}
\hline \multirow{3}{*}{ البحموع } & \multicolumn{6}{|c|}{ تغطية التخصص الدقيق } & \multirow{3}{*}{ الفئات } \\
\hline & \multicolumn{2}{|c|}{ كلا } & \multicolumn{2}{|c|}{ احيانا } & \multicolumn{2}{|c|}{ نعم } & \\
\hline & النسبة & التكرار & $\%$ & التكرار & $\%$ & التكرار & \\
\hline Ir & \%ro & $r$ & rז\% & $\varepsilon$ & $\%\{r$ & 0 & التدريسيين \\
\hline$\varepsilon$. & $\% \backslash \varepsilon$ & 7 & \%「ᄉ & 11 & $\% 0 \wedge$ & r & الطلبة \\
\hline or & $\% \backslash \mathrm{V}$ & 9 & $\%$ \% & 10 & $\%$ o & rᄉ & البحموع \\
\hline
\end{tabular}

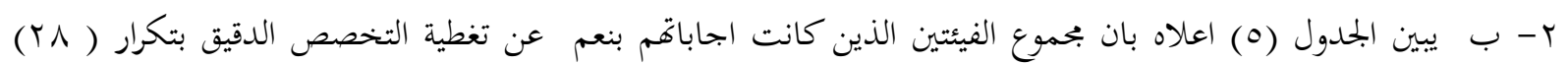

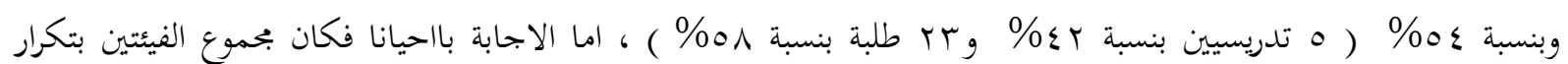

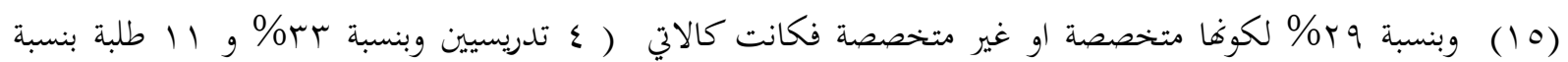

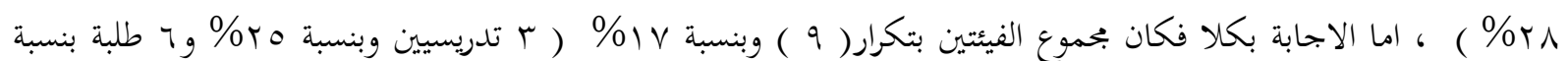
. $(\%) \leqslant$

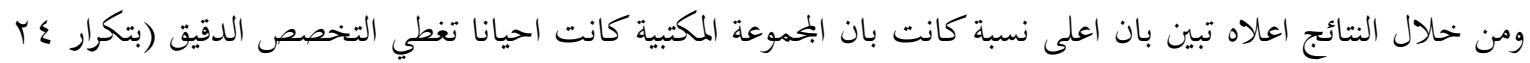

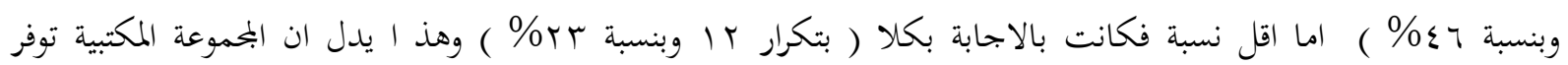
التخصص الدقيق وخاصة ان المكتبة متخصصة لكلية العلوم ومن ضمن التخصصات يوجد قسم علوم كيمياء . جدول رقم (ד) بيين الكتب التي تدعم المنهج الدراسي

\begin{tabular}{|c|c|c|c|c|c|c|c|}
\hline \multirow{3}{*}{ المجموع } & \multicolumn{6}{|c|}{ دعم المنهج الدراسي } & \multirow{3}{*}{ الفئات } \\
\hline & \multicolumn{2}{|c|}{ كلا } & \multicolumn{2}{|c|}{ الحيانا } & \multicolumn{2}{|c|}{ نعم } & \\
\hline & النسبة & التكرار & $\%$ & التكرار & $\%$ & التكرار & \\
\hline Ir & $\% \backslash \mathrm{V}$ & r & \%ro & r & $\% \circ \wedge$ & v & التدريسيين \\
\hline$\varepsilon$. & $\% \mathrm{v}$ & $r$ & $\%$ r. & $\wedge$ & $\% v r$ & rq & الطلبة \\
\hline or & $\% 1$. & 0 & \%r & 11 & $\% 79$ & $r$ & ابلمموع \\
\hline
\end{tabular}


ץ- ت يبين الجدول (T) اعلاه بان البمموعة المكتبية كانت تدعم المنهج الدراسي فقد كان بحموع الفيئتين الذين اجابو بنعم

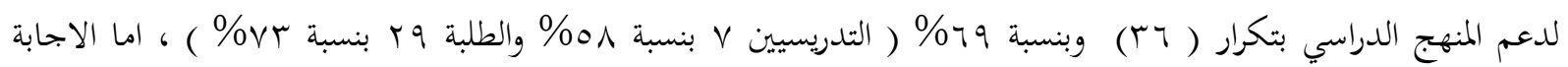

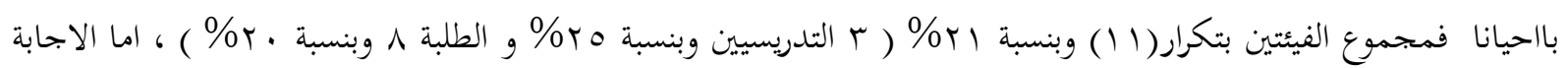

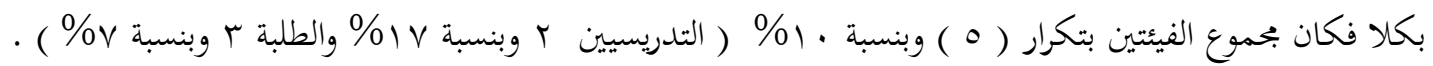

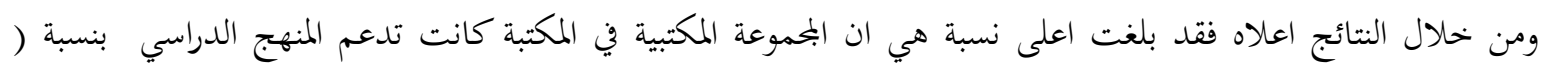

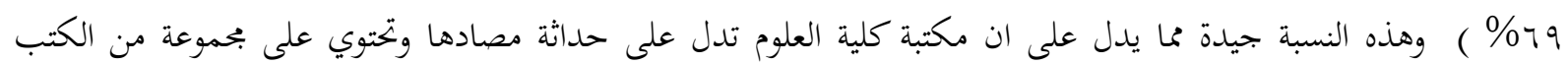

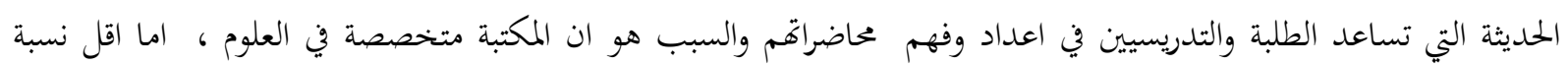
فكانت (\% ) بانها لاتدعم المنهج الدراسي . جدول رقم (V) بيين الكتب التي تدعم متطلبات البحث العلمي

\begin{tabular}{|c|c|c|c|c|c|c|c|}
\hline \multirow{3}{*}{ 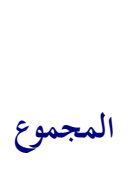 } & \multicolumn{6}{|c|}{ دعم متطلبات البحث العلمي } & \multirow{3}{*}{ الفئات } \\
\hline & \multicolumn{2}{|c|}{ كلا } & \multicolumn{2}{|c|}{ احيانا } & \multicolumn{2}{|c|}{ نعم } & \\
\hline & النسبة & التكرار & $\%$ & التكرار & $\%$ & التكرار & \\
\hline ir & $\% 9$ & 1 & \%rr & $\varepsilon$ & $\% \circ \wedge$ & $v$ & التدريسيين \\
\hline$\varepsilon$. & $\% \mathrm{~V}$ & $r$ & \%rr & ir & $\% 7$. & $T \varepsilon$ & الطلبة \\
\hline or & $\% v$ & $\varepsilon$ & \%rr & IV & $\%$ \%. & $r$ & البحموع \\
\hline
\end{tabular}

ץ- ث يبين الجدول (V) اعلاه بان البمموعة المكتبية كانت تدعم متطلبات البحث العلمي فقد كان بحموع الفيئتين الذين

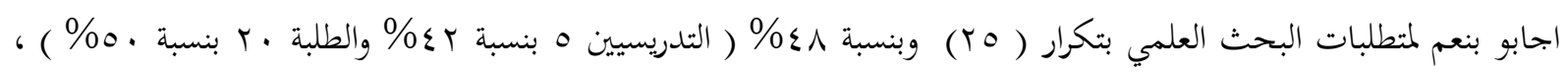

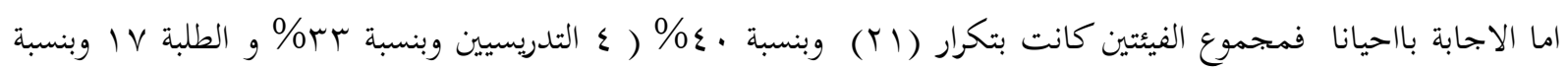

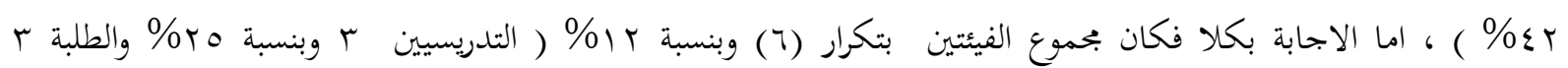
وبنسبة\%). ومن خلال النتائج اعلاه فقد بلغت اعلى نسبة هي ان المجموعة المكتبية في المكتبة كانت تدعم متطلبات البحث العلمي بنسبة (^^^\% ) وهذه النسبة جيدة مما يدل على ان مكتبة كلية العلوم تحتوي على مجموعة من الكتب التي تساعد الطلبة

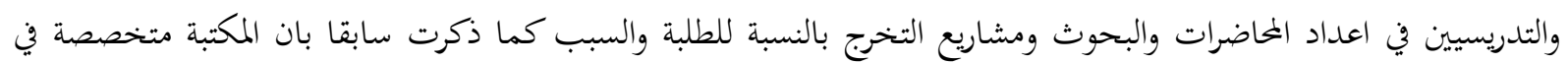

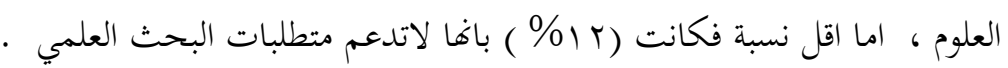

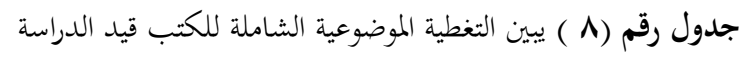

\begin{tabular}{|c|c|c|c|c|c|c|c|}
\hline \multirow{3}{*}{ البحموع } & \multicolumn{6}{|c|}{ التغطية الموضوعية الشاملة } & \multirow{3}{*}{ الفئات } \\
\hline & \multicolumn{2}{|c|}{ كلا } & \multicolumn{2}{|c|}{ احيانا } & \multicolumn{2}{|c|}{ نعم } & \\
\hline & النسبة & التكرار & $\%$ & التكرار & $\%$ & التكرار & \\
\hline IT & \%ro & $r$ & $\% \backslash v$ & r & $\% 0 \wedge$ & v & التدريسيين \\
\hline$\varepsilon$. & $\% 10$ & 7 & \%ro & 1. & $\% 7$. & $r \leqslant$ & 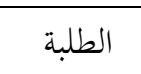 \\
\hline or & $\% \backslash \mathrm{V}$ & 9 & \%rr & ir & $\%$ ч. & $\mu$ & البحموع \\
\hline
\end{tabular}


ب-ج يبين الجدول (^) اعلاه بان البحموعة المكتبية كانت ذات تغطية موضوعية شاملة فقد كان بحموع الفئات الذين اجابو

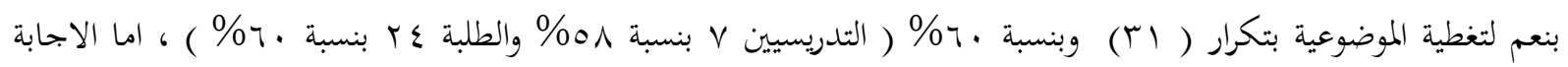

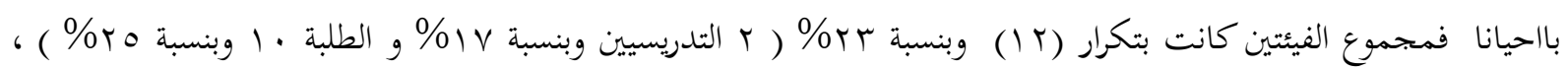

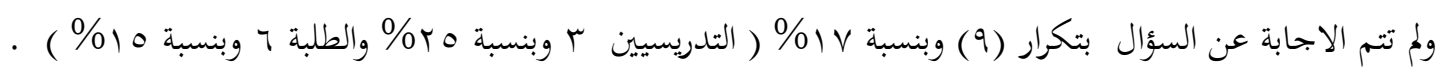
جدول رقم (9) بيين التوازن الموضوعي للكتب قيد الدراسة لتخرار (ه) وبنسبة

\begin{tabular}{|c|c|c|c|c|c|c|c|}
\hline \multirow{3}{*}{ المجموع } & \multicolumn{6}{|c|}{ توازن موضوعات الكتب } & \multirow{3}{*}{ الفئات } \\
\hline & \multicolumn{2}{|c|}{ كلا } & \multicolumn{2}{|c|}{ احيانا } & \multicolumn{2}{|c|}{ نعم } & \\
\hline & النسبة & التكرار & $\%$ & التكرار & $\%$ & التكرار & \\
\hline Ir & $\% 17$ & r & \%ry & $r$ & $\% \circ \wedge$ & V & التدريسيين \\
\hline$\varepsilon$. & \%rV & 11 & \%ro & 1. & $\% \leqslant \wedge$ & 19 & الطلبة \\
\hline or & \%ro & r & \%ro & ir & $\%$ & $r 4$ & البحموع \\
\hline
\end{tabular}

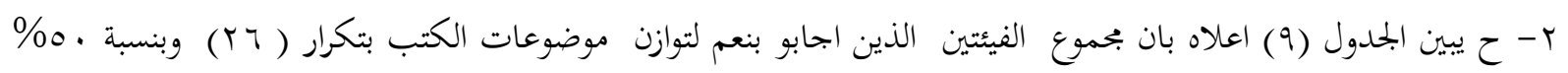

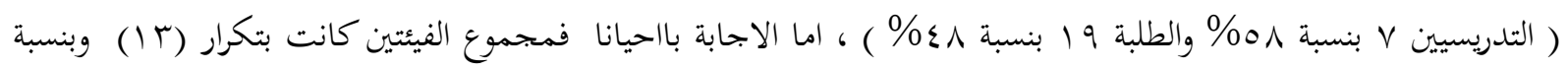

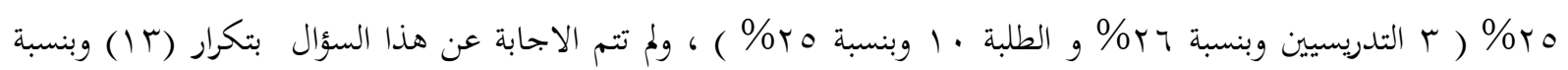

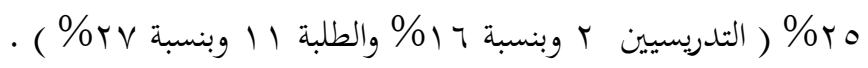
جدول رقم (• (1) يبين التزود باخر المستجدات العلمية في حقل التخصص

\begin{tabular}{|c|c|c|c|c|c|c|c|}
\hline \multirow{3}{*}{ المجموع } & \multicolumn{6}{|c|}{ التزويد باخر المستجدات العلمية } & \multirow{3}{*}{ 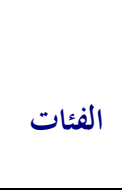 } \\
\hline & \multicolumn{2}{|c|}{ كلا } & \multicolumn{2}{|c|}{ 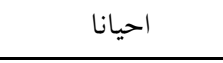 } & \multicolumn{2}{|c|}{ نعم } & \\
\hline & النسبة & التكرار & $\%$ & التكرار & $\%$ & التكرار & \\
\hline Ir & $\% \backslash \mathrm{V}$ & r & \%rr & $\varepsilon$ & $\% 0$. & 7 & التدريسيين \\
\hline$\varepsilon$. & \%r. & $\wedge$ & \%r. & Ir & $\% 0$. & $r$. & الطلبة \\
\hline or & $\% \backslash 9$ & 1. & \% & 17 & $\%$. & $r 7$ & البحموع \\
\hline
\end{tabular}

ץ- خ يبين الجدول (• (1) اعلاه بان بحموع الفيئتين الذين اجابو بنعم للتزود باخر المستجدات العلمية في حقل الاختصاص

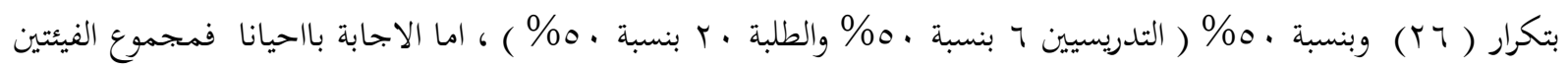

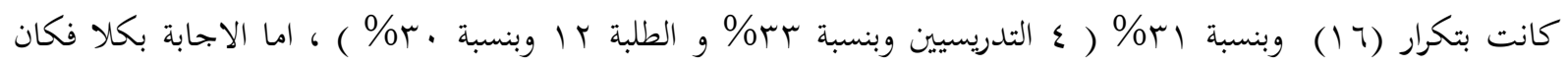

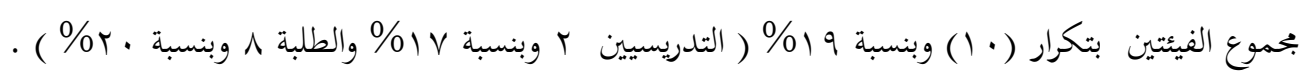
جدول رقم (11) يبين تنوع موضوعات وعناوين الكتب لينبن

\begin{tabular}{|c|c|c|c|c|c|c|c|}
\hline \multirow{3}{*}{ 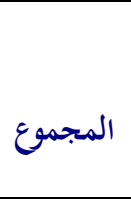 } & \multicolumn{6}{|c|}{ تنوع موضوعات وعناوين الكتب } & \multirow{3}{*}{ الفئات } \\
\hline & \multicolumn{2}{|c|}{ كلا } & \multicolumn{2}{|c|}{ 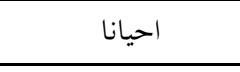 } & \multicolumn{2}{|c|}{ نعم } & \\
\hline & | - النسبة & 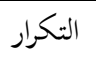 & $\%$ & 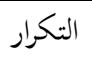 & $\%$ & 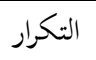 & \\
\hline Ir & $\% \backslash \mathrm{V}$ & r & \%ro & $r$ & $\% \circ \wedge$ & V & التدريسيين \\
\hline$\varepsilon$. & $\% \backslash \mathrm{V}$ & V & $\% r$. & $\Lambda$ & \%דr & ro & الطلبة \\
\hline or & $\% \backslash \mathrm{V}$ & 9 & $\%$ \% & 11 & $\%$ \%т & rt & البمموع \\
\hline
\end{tabular}




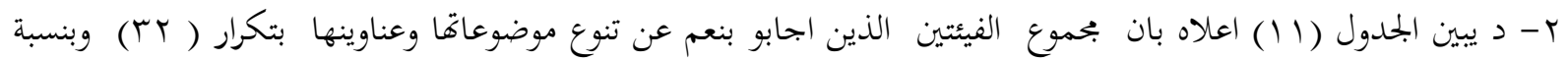

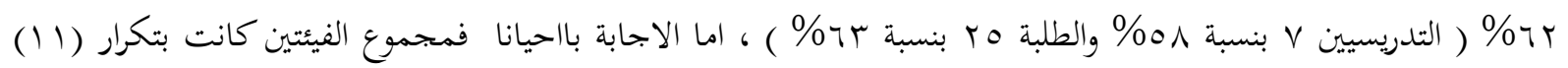

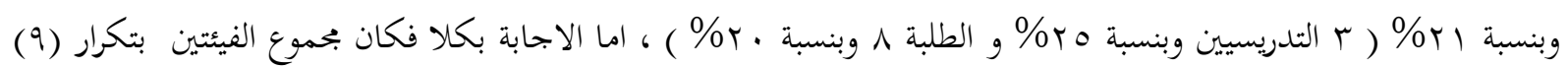

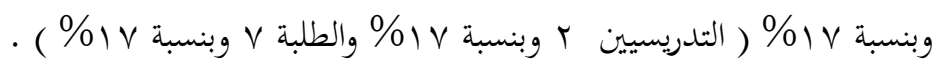
جدول رقم (r ( ) يبين امكانية الاستغناء عن المكتبات الخاصة او الانترنت

\begin{tabular}{|c|c|c|c|c|c|c|c|}
\hline \multirow{3}{*}{ 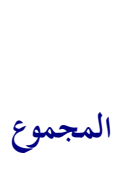 } & \multicolumn{6}{|c|}{ الاستغناء عن المكتبات الخاصة والانترنت } & \multirow{3}{*}{ 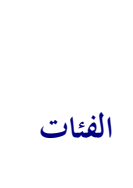 } \\
\hline & \multicolumn{2}{|c|}{ كلا } & \multicolumn{2}{|c|}{ 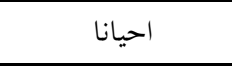 } & \multicolumn{2}{|c|}{ نعم } & \\
\hline & النسبة & التكرار & $\%$ & التكرار & $\%$ & التكرار & \\
\hline ir & $\%$ ro & $r$ & $\%$ & $\varepsilon$ & $\% \varepsilon r$ & 。 & التدريسيين \\
\hline$\varepsilon$. & $\% r$. & $\wedge$ & $\%$ r. & Ir & $\% 0$. & $r$. & الطلبة \\
\hline or & $\%$ \% & 11 & $\%$ & 17 & $\%$ \% & ro & البمموع \\
\hline
\end{tabular}

ץ- ذ يبين الجدول (r ا) اعلاه بان بحموع الفيئتين الذين اجابو بنعم عن امكانية العيينة للاستغناء عن استخدام مكتباتم

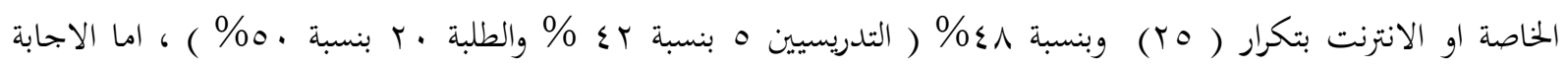

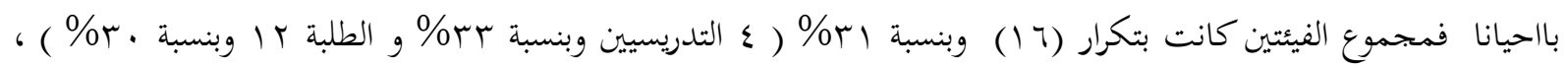

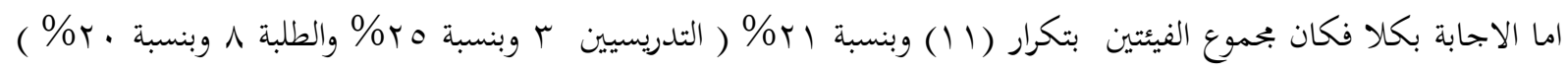

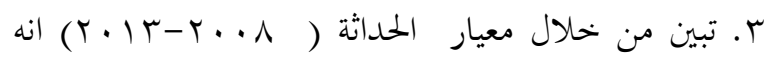

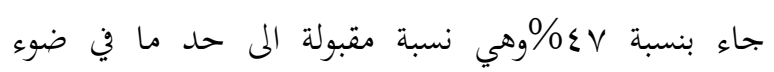
ميزانيتها المحدودة . ع. احتل معيار مكانة الناشر لمؤسسة او هيئة بتحارية

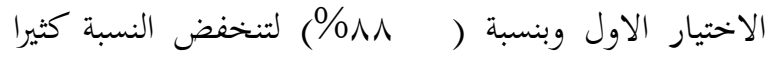

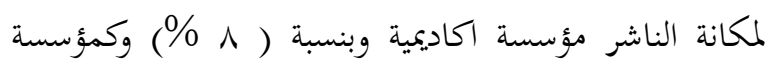

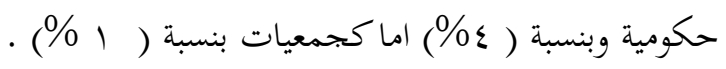

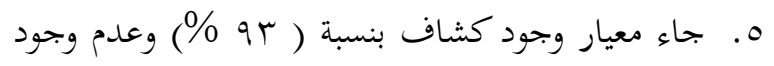
كشاف بنسبة ( \%V) ويعود السبب في ذلك ان البمموعة

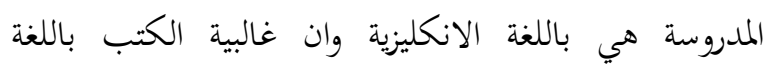

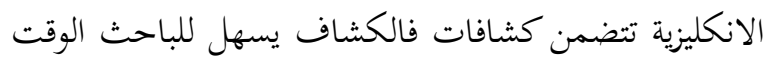
والجهد في الوصول للمعلومات .

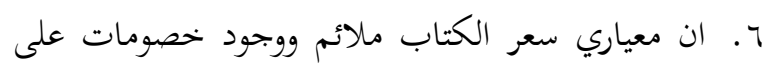
السعر جاء بنسبة ( . . 1\%\%) . V. حقق معيار اتاحة المصادر البديلة ( الاقراص الليزرية )

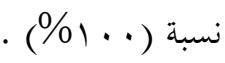

خرج البحث بعدد من النتائج بحملها بما يلي :

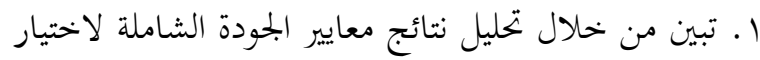

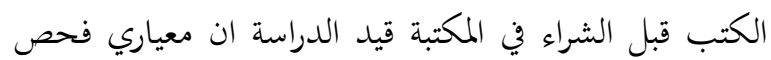

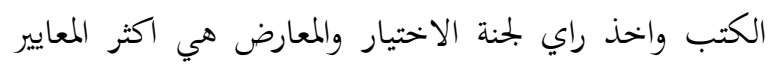

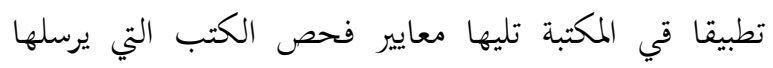

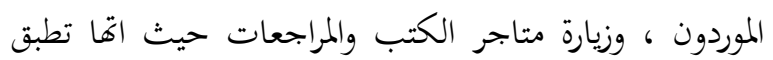
احيانا ، اما معايير فحص النسخ والاعارة بين المكتبات غير ورتير مطبقة . r. من خلال تحليل معيار التغطية ( تقييم المختوى ) ان عدم

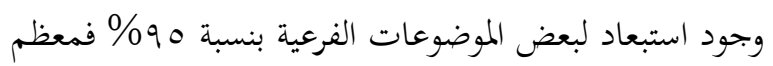
عناوين الكتب لمؤلفين معروفين في حقل الكيمياء ومن ثم يليه

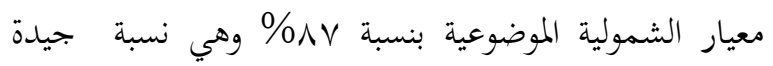

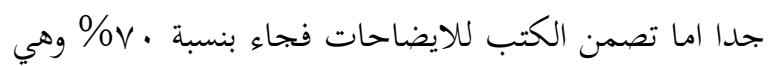

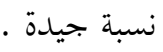


ج. التاكيد على معيار الحداثة بصورة اكبر بحيث تكون

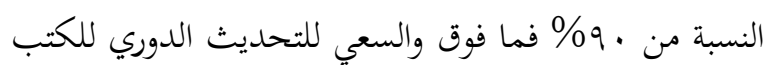

ح. التاكيد على الخصومات التي يمكن ان يقدمها الناشرين

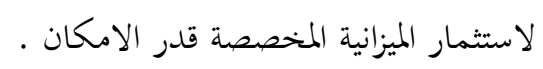

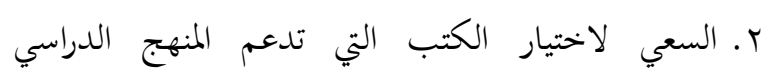

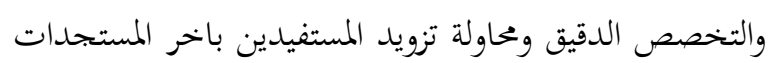

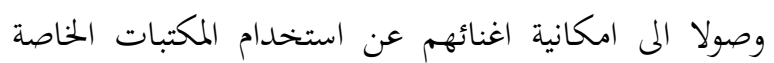
والانترنت . وصولا

r. ضرورة الاشتراك بالانترنت او على الاقل توفير بعض

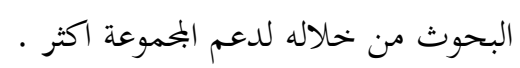

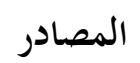

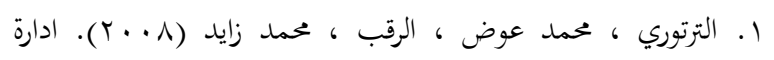

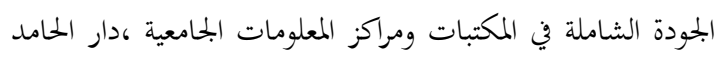

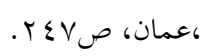

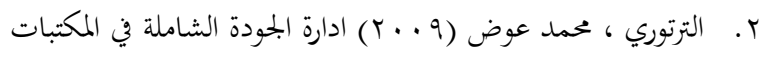

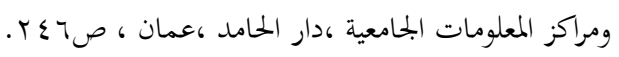

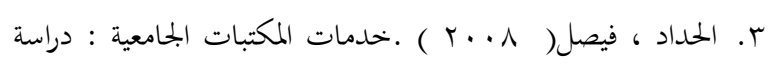

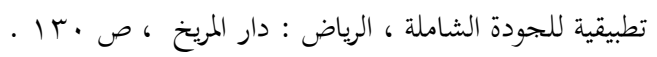

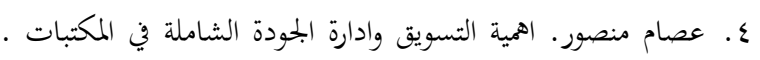

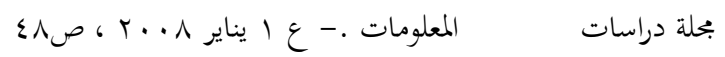

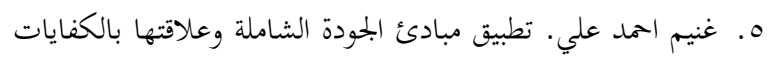
المهنية لدى المعلمين في المدارس الثانوية الحكومية للبنين بالمدينة المنورة . - بملة جامعة ام القرى للعلوم التربوية والاجتماعية

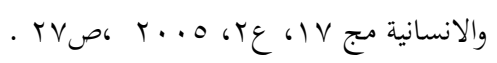
T. قنديلجي ، عامر ابراهيم ، ربحي مصطفى عليان ، السامرائي ، ليمان

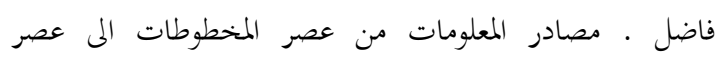

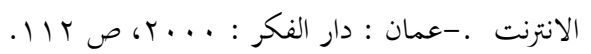

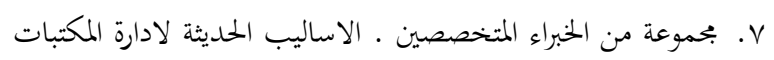

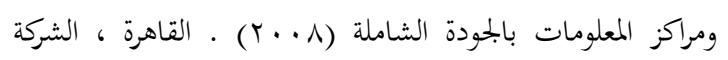

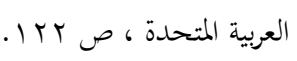

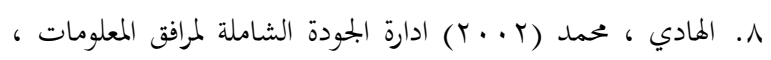

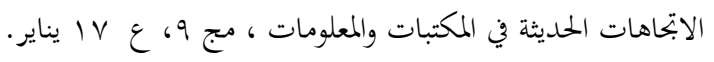

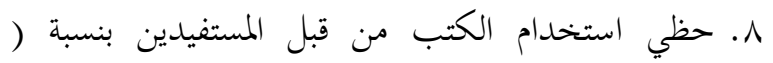

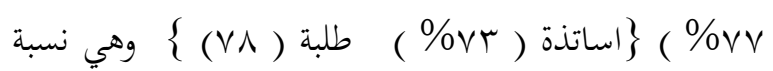

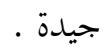
9 9. احتل معيار دعم المنهج الدراسي الاكثر وبنسبة ( 79\%ة

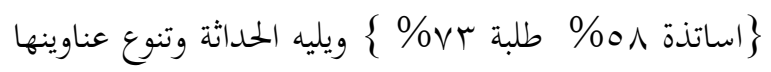

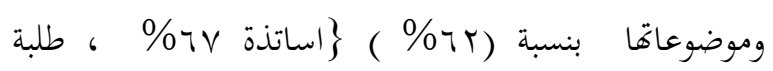

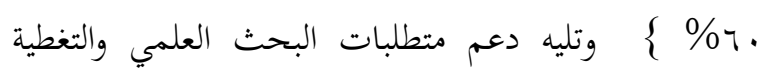

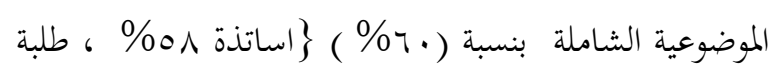
.

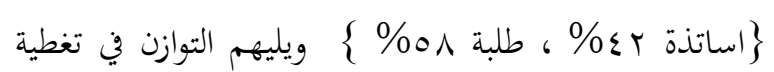

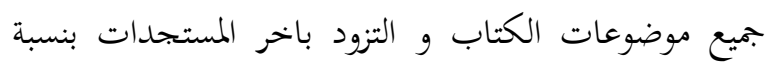

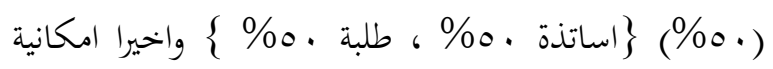

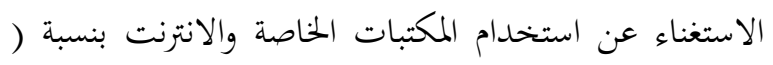

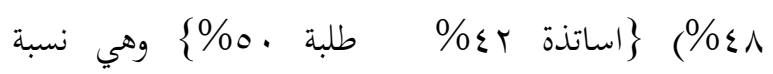
منخفضة التوصيات : ا ـ ضرورة الالتزام بتطبيق معايير الجودة الشاملة المعتمدة في

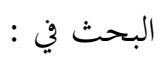
أ. في عملية اختيار الكتب خاصة قبل شرائها ففي ظل الميزانيات المحدودة لابد للمكتبة من السعي الحثيث لاستثمارها

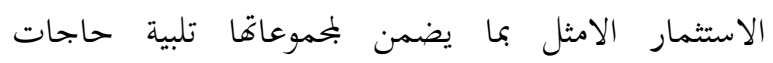
مستفيديها دون هدر في مواردها المحدودة .

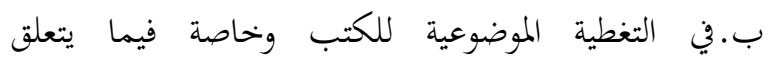
بالشمولية وعدم استبعاد للموضوعات الفرعية . ت. التاكيد على اختيار الكتب التي تتضمن الايضاحات والجداول والرسوم التي تدعم موضوع الكتاب. ث.اعتماد مكانة الناشر العلمية وخاصة لناشري المؤسسات

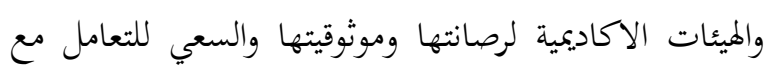
عدة ناشرين وليس الاقتصار على ناشرين محددين . 
Information ,South Caucasian 9. Corak , k .(1993) Organization for Regional Library conference Quality Planning for Higher Proceedings Tbillissi ,may $1 \quad$ Education.U.S.A.-Vol 21,No9 . p22.

12. Riggs,D.E (1992).TQM: Quality 10. Mastters, denise G( 2013). TotalQuality Improvement in new Clothes,college Research Libraries, Vol.53,No.6, PP. 67

Management in Libraries . Available in www: ERIC Digestsml.com

11. Meterevli ,M.(2004) planning in library Management in library Access to

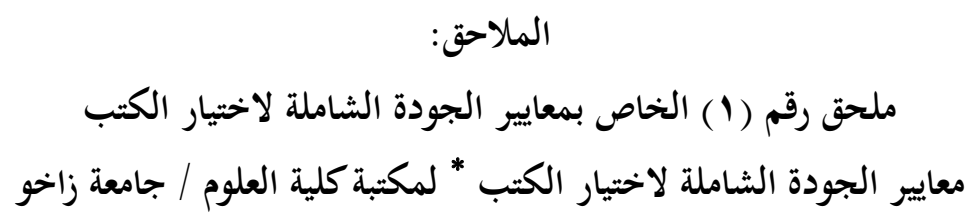

اولاً : تقييم مصادر المعلومات قبل الشراء :

\begin{tabular}{|c|c|c|c|}
\hline كلا & احيانا & نعم & التقييم \\
\hline
\end{tabular}

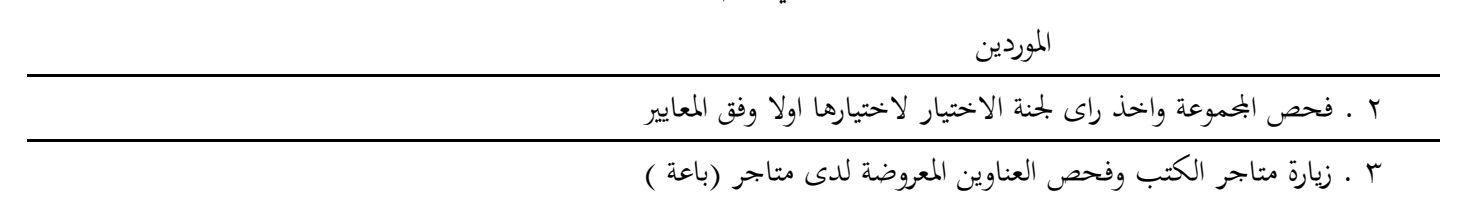

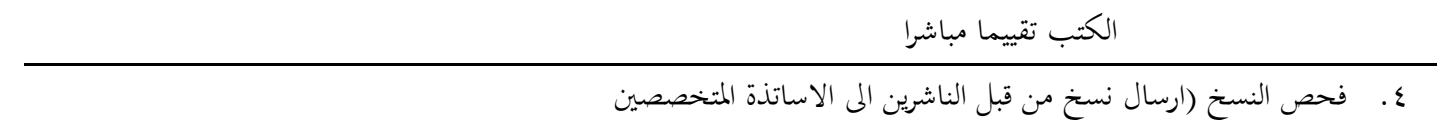

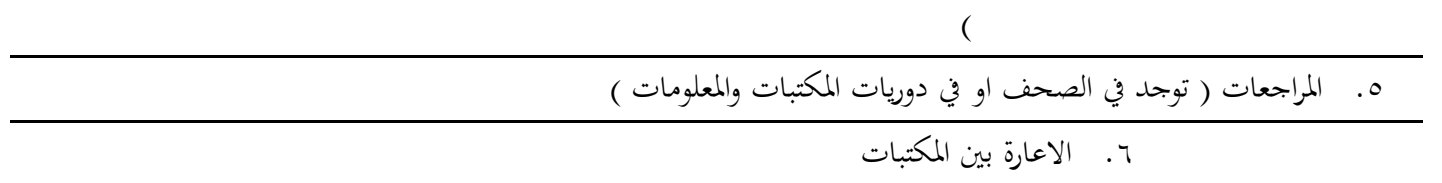

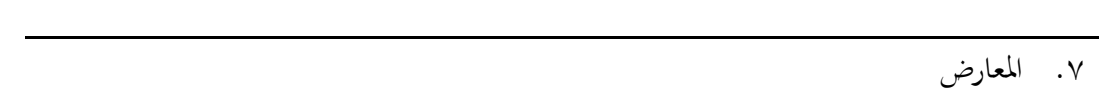

المعيار ماذوذمن المصدر : مجمو عة من الخبر اء المتخصصين ـ الاساليب الحديثة لادارة المكتبات ومر اكز المعلومات .ـ القاهرة : الثركة العربية 


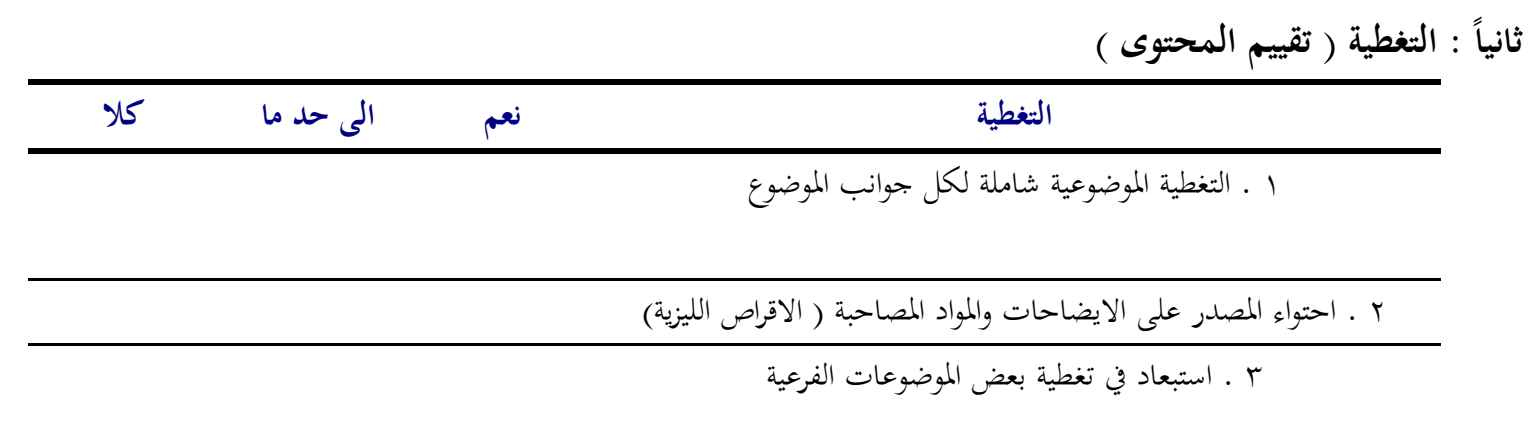

ثالثاً : الحداثة

\begin{tabular}{|c|c|c|c|}
\hline 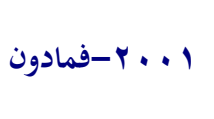 & $\begin{array}{c}-r \cdot r \\
r \cdot \cdot V\end{array}$ & $\begin{array}{c}-r \cdot r \\
r \cdot 1 r\end{array}$ & 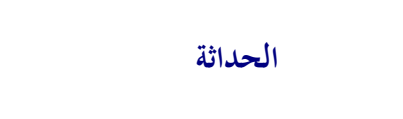 \\
\hline & & & 1. حداثة مصادر المعلومات \\
\hline \multirow[t]{2}{*}{ كلا } & 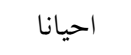 & نعم & \\
\hline & & & r.هل يتم التحديث على فترات ثابتة \\
\hline
\end{tabular}

رابعاً : الجودة والكفاءة

\begin{tabular}{|c|c|c|c|}
\hline كلا & 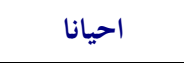 & 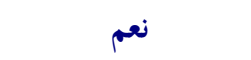 & \\
\hline & & & 1 ـاحتواء المصادر على الكشافات \\
\hline اي شكل اخر & كشاف منفصل & كشاف مع الكتاب او & r ـ شكل الكشاف \\
\hline \multirow[t]{2}{*}{ هجائيا بالموضوع } & هجائيا بالعنوان & هجائيا بالمؤلف & \\
\hline & & & r ـ نوع الكشاف \\
\hline
\end{tabular}


سادساً : التكاليف

\begin{tabular}{|c|c|c|c|}
\hline كلا & 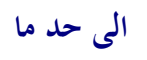 & 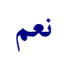 & \\
\hline & & & 1 ـ ـ سعر شراء الكتب مرتفع \\
\hline & & & r ـ كلفة الاشتراك بالدوريات مرتفع \\
\hline & & & r ـ هل هناك مصادر اخرى للحصول على المصدر بكلفة اقل \\
\hline & & & ـ ـ هل هناك خصم على سعر المصدر \\
\hline
\end{tabular}

سابعاً : البدائل المختلفة لمصادر المعلومات

\begin{tabular}{|c|c|c|c|c|c|c|}
\hline \multicolumn{3}{|c|}{ المعلومات المتاحة على الانترنت التي } & \multicolumn{3}{|c|}{ قواعد البيانات المتاحة على اقراص } & \multirow{2}{*}{ ا مصادر المعلومات البديلة (الالكترونية ) } \\
\hline كلا & 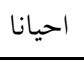 & 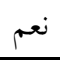 & كلا & 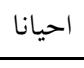 & نعم & \\
\hline \multirow[t]{2}{*}{ كلا } & احيانا & نعم & كلا & 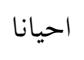 & نعم & r ـ مصادر المعلومات التي يمكن الاستغناء عنها \\
\hline & & & & & & مقابل الحصول على مصادر جديدة \\
\hline
\end{tabular}

ثامناً : معيار اللغة

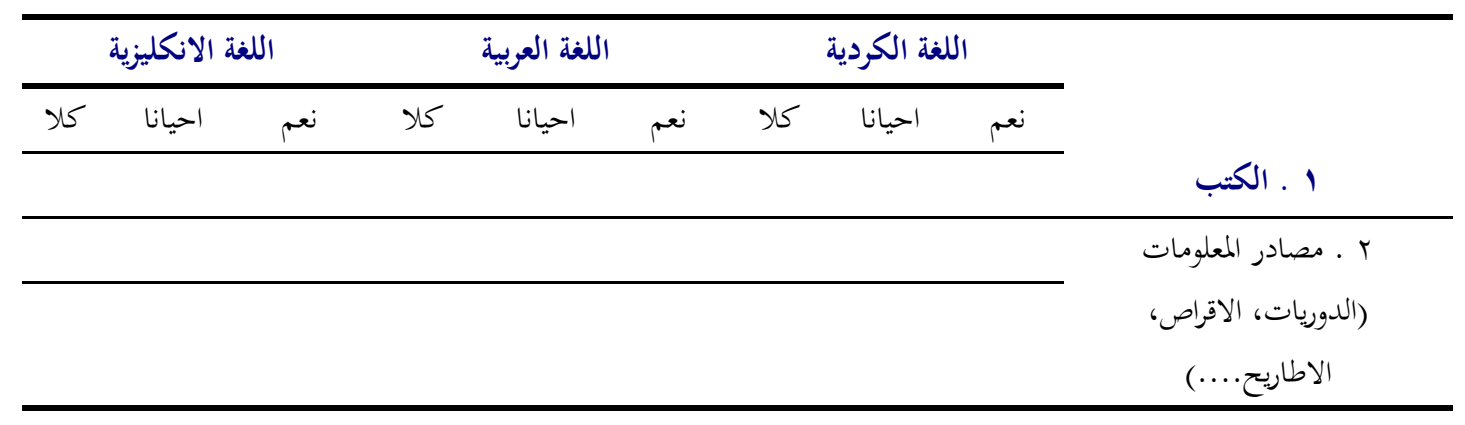




\section{ملحق رقم (r) (1) (1) \\ استمارة استبيان}

الزملاء الاساتذة ومنتسيبو القسم الافاضل الطلبة الاعزاء... تحية طيبة ..

اروم في اعداد بحثي الموسوم " معايير ادارة الجودة الشاملة للمجموعة المكتبية لمكتبة كلية العلوم /جامعة زاخو : دراسة تحليلية "

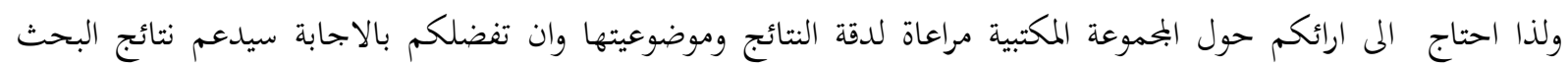
علمياً. مع فائق الشكر والتقدير والامتنان

الباحثة

ملاحظة الرجاء وضع علامة ( $\checkmark$ ) صح امام الاجابة المناسبة لك .

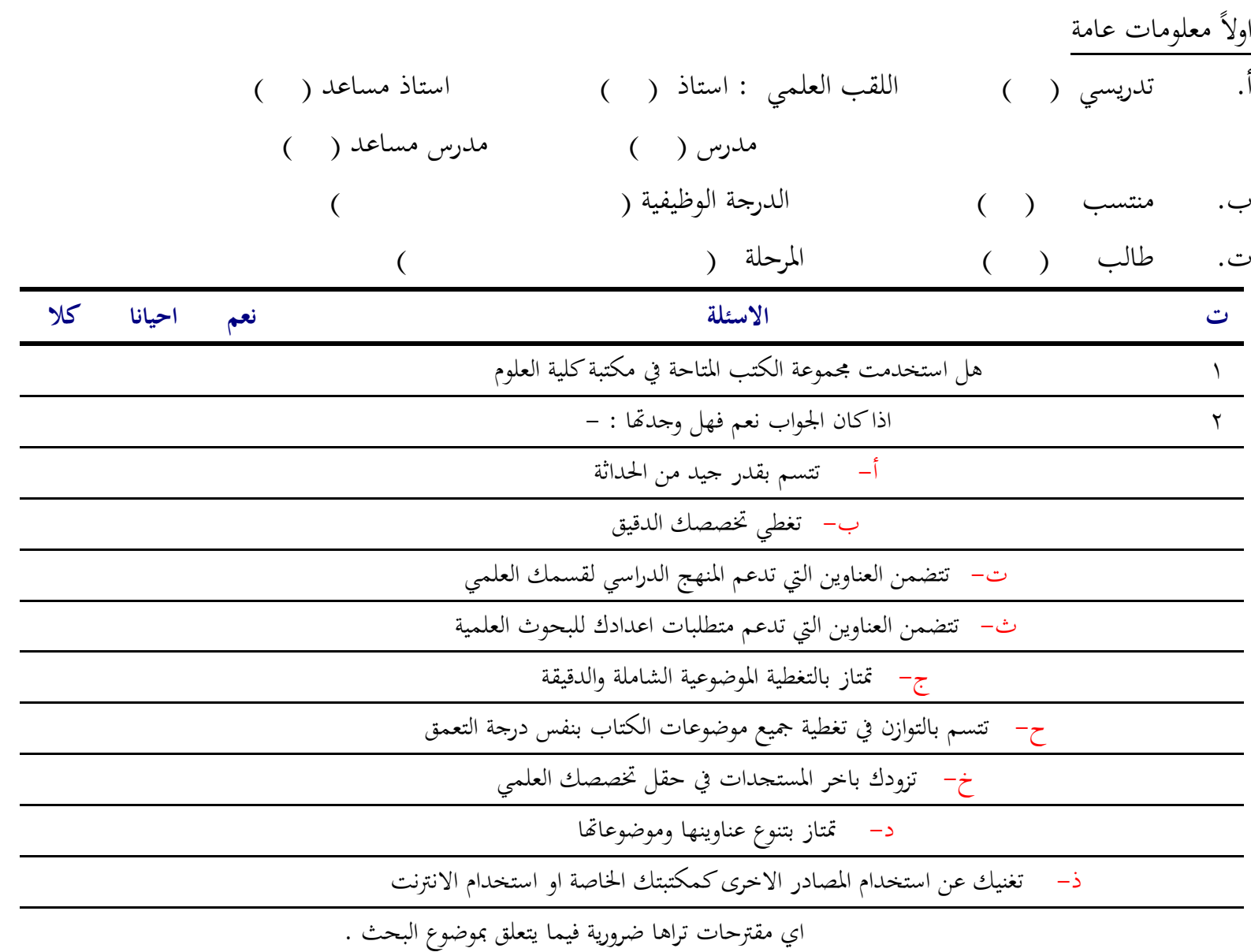




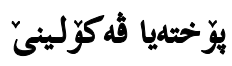

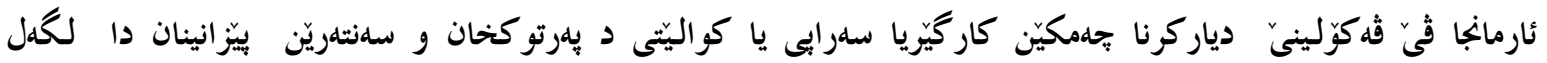

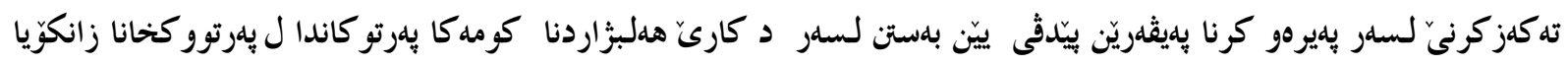

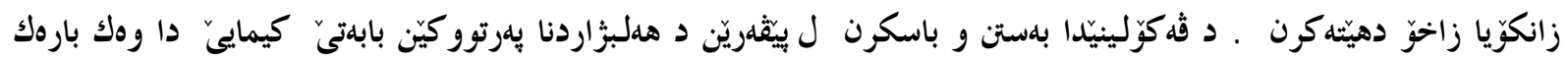

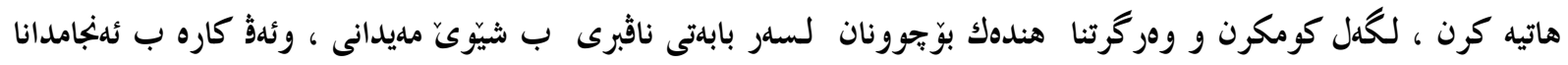

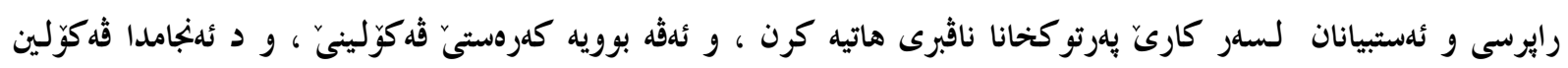
كهملشتيه ثان خالان :

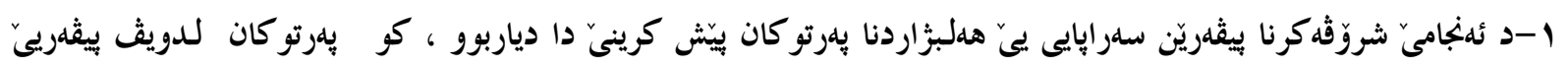

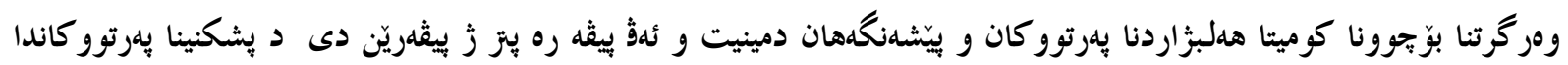

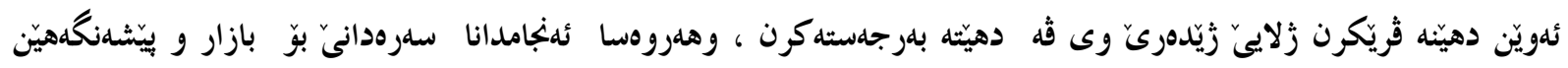

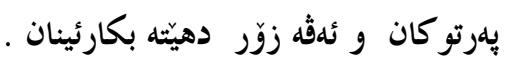

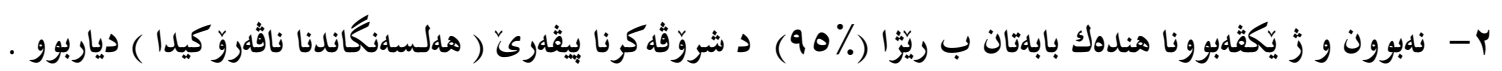

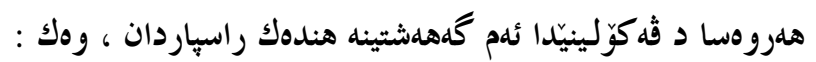

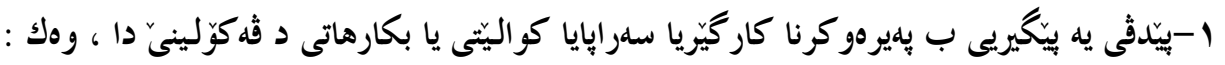

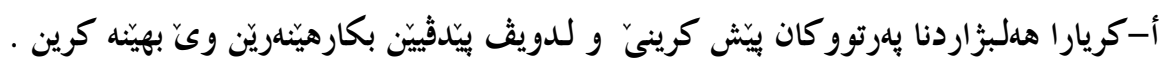

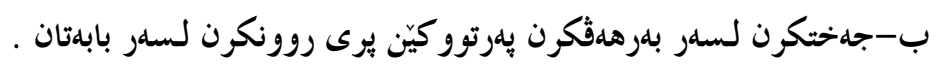

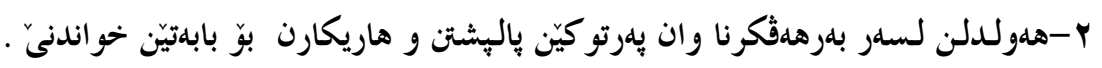

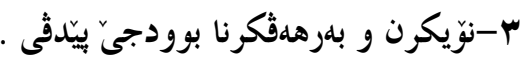

\section{Abstract}

The Research aims to identify the total Quality management in libraries and information centers according applied standards in book selection process available in library faculty of science in university of Zakho. The case study is depended on actual survey for books in chemistry science by used group of standards on selection process. The survey method is used for users opinions and interview with staff in the library and selection files and questionnaires tools for collecting data .

The Research results are :

1. The book checking and selection committee is the first standard applied .

2. The collection evaluate remove committee is the first standard recent $95 \%$.

The important recommendations are :

1. Its necessary to applied TQM used in this research in :

a. Book selection process before buying it to insure users needs.

b. Select the books contains illustration .

2. Select books cover curriculum and specific field .

3. Modernity and Investment of the allocated budget. 